\title{
Targeted adjustment of residual stresses in hot-formed components by means of process design based on finite element simulation
}

Received: 14 October 2020 / Accepted: 22 February 2021 / Published online: 26 March 2021

(C) The Author(s) 2021

\begin{abstract}
The aim of this work is to generate an advantageous compressive residual stress distribution in the surface area of hot-formed components by intelligent process control with tailored cooling. Adapted cooling is achieved by partial or temporal instationary exposure of the specimens to a water-air spray. In this way, macroscopic effects such as local plastification caused by inhomogeneous strains due to thermal and transformation-induced loads can be controlled in order to finally customise the surface-near residual stress distribution. Applications for hot-formed components often require special microstructural properties, which guarantee a certain hardness or ductility. For this reason, the scientific challenge of this work is to generate different residual stress distributions on components surfaces, while the geometric as well as microstructural properties of AISI 52100 alloy stay the same. The changes in the residual stresses should therefore not result from the mentioned changed component properties, but solely from the targeted process control. Within the scope of preliminary experimental studies, tensile residual stresses in a martensitic microstructure were determined on reference components, which had undergone a simple cooling in water (from the forming heat), or low compressive stresses in pearlitic microstructures were determined after simple cooling in atmospheric air. Numerical studies are used to design two tailored cooling strategies capable of generating compressive stresses in the same components. The developed processes with tailored cooling are experimentally realised, and their properties are compared to those of components manufactured involving simple cooling. Based on the numerical and experimental analyses, this work demonstrates that it is possible to influence and even invert the sign of the residual stresses within a component by controlling the macroscopic effects mentioned above.
\end{abstract}

Keywords Residual stresses $\cdot$ Hot forming $\cdot$ Tailored cooling $\cdot$ FE-based process design

\section{Introduction}

Forging processes for complex and highly stressed components have become well-established in industrial mechanical engineering [1]. The high forming temperatures of up to $1250{ }^{\circ} \mathrm{C}$ cause a reduction in the yield stress of the material, which favours material flow and thus allows the production of geometrically sophisticated components. Furthermore, the plastic deformations in forged components are significantly more extensive in relation to elastic deformations, making elastic recovery after deformation negligible [2]. In addition, the forging process fosters a fine microstructure in the material, giving considerable strength to the component [3]. Despite all its advantages, hot forming is a complex thermo-mechanical process comprising numerous material and process-specific parameters that are subject to a variety of interactions, so that numerical methods for process design are crucial and challenging at the same time [4]. As shown in Fig. 1a, the phenomena

B.-A. Behrens $\cdot$ K. Brunotte $\cdot$ H. Wester · C. Kock $(\varangle)$

Institut Fuer Umformtechnik und Umformmaschinen, Leibniz Universität Hannover, An der Universität 2, 30823 Garbsen, Germany

e-mail: kock@ifum.uni-hannover.de 


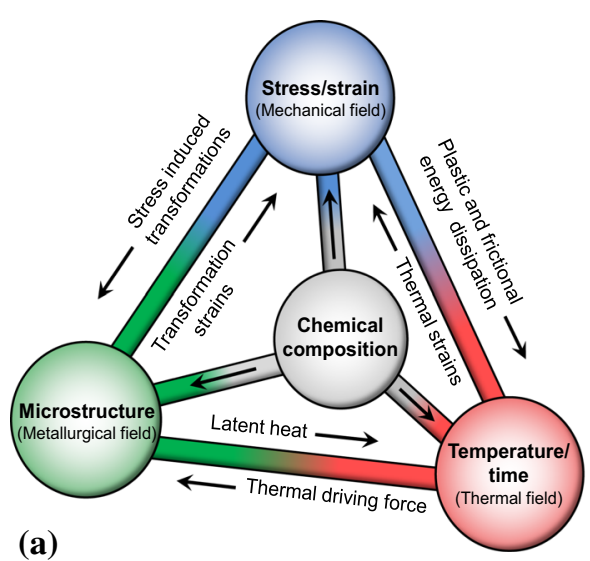

$$
d \varepsilon_{i j}^{t o t a l}=d \varepsilon_{i j}^{e l}+d \varepsilon_{i j}^{p l}+d \varepsilon_{i j}^{t h}+d \varepsilon_{i j}^{t r}+d \varepsilon_{i j}^{t p}
$$

$d \varepsilon_{i j}^{e l}$ : elastic strain increment

$d \varepsilon_{i j}^{p l}:$ plastic strain increment

$d \varepsilon_{i j}^{t h}$ : thermal strain increment

$d \varepsilon_{i j}^{t r}$ : transformation related strain increment

$d \varepsilon_{i j}^{t p}$ : transformation plasticity strain increment

(b)

Fig. 1 Interrelated thermo-mechanical-metallurgical material phenomena during thermo-mechanical processing of steel (a) and basic principles of the additive strain decomposition method (b), [8]

occurring during the hot forming of steels can be attributed to thermal, metallurgical and mechanical effects based on the chemical composition of the alloy. These different effects are often considered in the finite element (FE) simulation of thermo-mechanical processes by means of additive strain decomposition, for instance in the works [5-7]. According to this method, the total strain increment is calculated from the sum of the strains separately caused by elastic-, plastic-, thermal-, transformation-induced and transformation-plasticity effects (Fig. 1b).

Against this background, it is obvious that especially the simulative prognosis of the residual stresses resulting from hot-forming processes represents a challenge, particularly since the stress distribution in the component can occur through an inhomogeneous distribution of each of the strain components arising from the five physical phenomena mentioned above. These residual stresses can significantly influence the performance of forged components [9]. Considering a static load case, it is obvious that the presence of residual tensile stresses leads to a reduced resistance of additional external tensile stresses. The areas of a component subjected to tensile residual stresses are thus more prone to crack initiation. Considering the dynamic load case, the residual stresses also have a significant impact on the service life of the components, since they also affect the mean or maximum value of each load cycle. The influence of residual stresses on failure is discussed in [10], for example. It is pointed out that compressive residual stresses in the surface can prevent damage and extend the life of a component. An example for the targeted use of residual stresses is the implementation of an additional process step to the hot-forming process chain aiming at generating residual compressive stresses in the surface to ensure the wear resistance of components [11]. These include glass-bead peening, water peening and lasershock peening, along with deep rolling and low-plasticity burnishing. Although the specific mechanics and mechanisms of these techniques vary, they share the common characteristic that localised plastic deformation of arbitrary engineering surfaces is used to induce compressive residual stresses near the surface. It should be noted that the stability of the residual stresses induced in components depends on operating influences such as thermal or mechanical loads [12]. Figure 2a clearly shows how residual compressive stresses can influence the fatigue strength properties of components. The alternating bending curves of stress amplitudes with respect to the number of cycles to the failure of smooth specimens from AISI 1045 (corresponds to DIN 1.1191) in ground condition and with additional shot peening after treatment are compared. Due to the residual compressive stresses induced by shot peening, the specimen shows significantly higher finite fatigue life as well as fatigue-strength properties.

To investigate the residual stress development in the forging process of gears, 40 components made of the material AISI 4320 (corresponds to DIN 1.5918) were examined in [13], Fig. 2b showing the extremes of the residual stresses in components $\mathrm{A}$ and $\mathrm{B}$. The depth curve $\mathrm{A}$ represents the residual stresses at the tooth root after hot forming and an additional shot-peening operation. Before the shot-peening operation, tensile residual stresses were present on the surface. Due to the additional treatment step in the process chain, a favourable residual stress distribution could be generated on the surface. In contrast, a favourable residual stress distribution was found at the tooth root of gear B immediately after hot forming without an additional shot-peening step. Such differences occur due to the varying process routes as a result of non-standardised production techniques [14]. This example illustrates both, the challenges as well as the potential of intelligent 
(a)

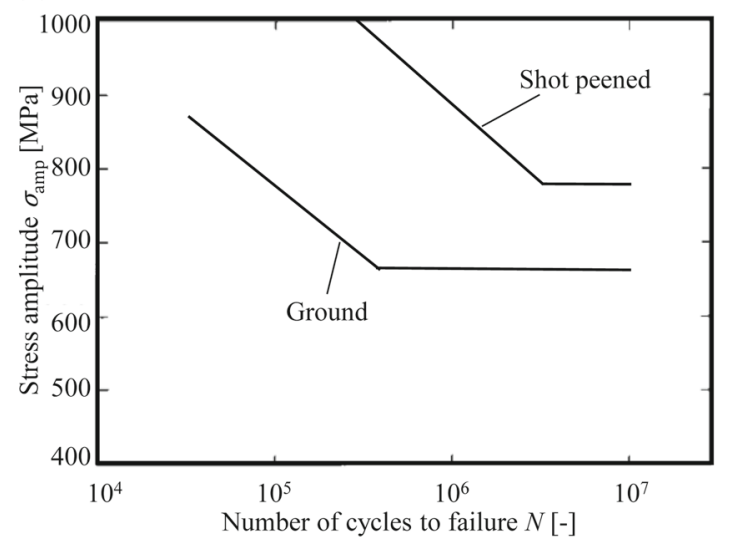

(b)

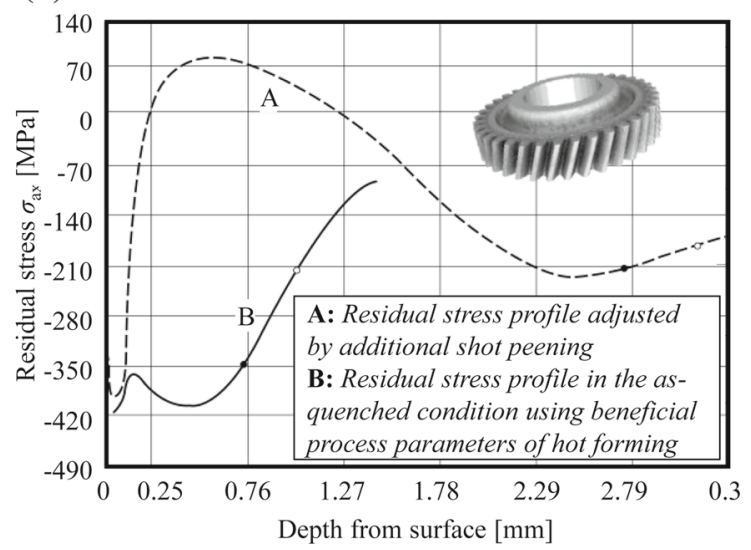

Fig. 2 Alternating bending curves of stress amplitude with respect to number of cycles to failure of smooth specimens from AISI 1045 in ground condition and with additional shot peening after treatment (a) [15] as well as the extremes in residual stress distributions on tooth roots found among 40 hot-formed gears using the steel AISI 3115 (b) [13]

process management. Assuming that a favourable residual stress distribution can be generated only by precisely controlling the process parameters, the subsequent operation step for improving component properties could be saved. Such a shortening of the process chain will result in a gain of time, costs and resource efficiency.

For the application of residual compressive stresses in connection with hot forming, some authors report on processes involving case hardening or induction hardening. These techniques pursue the aim of triggering a martensitic phase transformation in the near-surface region, resulting in a strain gradient in the component due to the higher specific volume of martensite compared to other phases like ferrite, pearlite or bainite prevailing in the core of the component. The expanded material in the surface area of the component is thus subject to compressive stress, while tensile stresses dominate in the core for reasons of equilibrium. In case-hardening processes, steels with a generally low carbon content of 0.1 to $0.2 \%$ are enriched with carbon atoms in the surface areas in order to increase the hardenability of this layer [16]. For instance, the studies [17-19] show that high compressive stresses can be generated in carburised steels by means of this method. A similar effect is achieved in induction hardening, where the skin effect arising from induction heating is used to partially heat the components, so that only the near-surface areas of the component are austenitised. During subsequent quenching, only these areas undergo volume expansions as a result of the martensitic transformation, in analogy to the carburised layer during case hardening. The most important advantages are short heat-treatment times, good repeatability concerning the quality of the hardened layer, small or negligible subsequent distortion and a minimum subsequent surface oxidation [20]. An analysis of the compressive stresses occurring in induction hardening processes is given in the publications [21-23]. However, a substantial drawback of these two techniques is that the treatments take place in an additional time- and energy-intensive step in the process chain, which involves reheating and quenching of the component after forging. Meanwhile, efforts are already being made to shorten the hot-forming process chain and to integrate heat treatment in the forging step [24]. Researchers in the work [25-27] report on the possibility of saving energy by performing the quenching and tempering directly from the forging heat. Due to the high forming temperatures, however, this may cause increased material loads leading to cracks. A further shortening of the process chain is the controlled cooling from the hot-forming heat, such as best-yield treatment. Here, the desired microstructure and material properties are achieved by controlled cooling from the forging heat. The so-called broken quenching process is used in industrial practice, in which a component is first cooled rapidly in a water bath just before the martensite start temperature Ms [28]. Subsequently, the component is cooled more slowly in an oil bath to prevent crack formation due to the lower heat-transfer coefficients. A more precise adjustment of the heat-transfer coefficients and thus of the temperature gradients is achieved in [29] and [30] by means of a cooling medium with added polymer solutions in customised concentrations. In addition, the works [31,32] and [33] show that the controlled cooling using a two-phase fluid flow on the basis of a water-air mixture has proved to be very flexible, since both comparatively low heat transfers as in gas quenching and high cooling rates like those in water cooling can be achieved. Thus, a surface tempering of austenitised components like gears [34] and pinion shafts [35] could be realised by controlled spray cooling, with the surface being quenched and tempered by means of the residual internal heat. The heat transfer during quenching is achieved by means of water spray finely atomised 
by compressed air sprayed onto the surface of the component. As a result of the atomisation, the surface of the water is significantly increased so that a higher heat transfer is achieved [36]. No current research results exist with regard to the targeted adjustment of residual stresses in the course of the heat treatment integrated in the forging step. However, some experimental as well as numerical investigations have been performed to analyse the residual stress development during the hardening of cylindrical components. The formation of residual stresses is attributed to an inhomogeneous plastification of the material as a result of temperature gradients and transformation-induced volume expansions. These in turn occur depending on material properties, geometric properties and cooling rates. Thus, in [37] the relationship between the resulting residual stresses on the cylinder surface as a function of Ms, cylinder diameter and quenching techniques referring to AISI 1045 is shown. In the study [38], common rules are derived for a prognosis of signs of residual stresses at the cylinder surface, which are based on the time of the turning point from thermally induced stresses together with the martensitic transformation timing during cooling.

In summary, it is shown that hot forming is an important element in industrial steel processing. The hotforming process chain offers significant potential for increasing service life by introducing compressive stresses in the component surface using controlled cooling concepts. A suitable option for the resource- and energyefficient production of these components is integrating heat treatment in the forging step for the direct induction of residual compressive stresses in the near-surface area with simultaneous shortening of the process chain. In further research work, spray cooling proved to be useful for investigating tailor-made forming applications since it allows for controlling and replicating the generated heat transfer. Based on this state of research, this publication aims at demonstrating the possibilities of applying compressive stresses by means of intelligent cooling strategies using a spray-cooling system integrated in the hot-forming process. To achieve this goal, both FE simulations and experimental examinations are carried out. A comprehensive material characterisation of the material AISI 52100 (corresponds to DIN 1.3505) is carried out, and a material model is created. The material model is initially used to analyse the development of residual stresses during simple water cooling or air cooling from the forging heat on the basis of a reference process of hot forming. It is shown that this process results in fully hardened components with martensitic microstructure and high tensile residual stresses on the surface or almost stress-free specimens with pearlitic microstructure. Following this, FE studies are used to demonstrate the methods for manufacturing the same martensitic and pearlitic components with residual compressive stresses in the near-surface area by using a partial or instationary cooling strategy with spray cooling. These four numerically considered process cases are realised experimentally, and the residual stresses on the component surfaces are determined by X-ray diffraction.

\section{Materials and methods}

As mentioned in introduction, the aim of this publication is to demonstrate the feasibility of hot-forming processes to manufacture components with beneficial residual stress distributions at the surface solely by forming with subsequent tailored cooling. In order to design the studies close to industrial reality, it is essential to consider the tailored cooling in connection with the preceding forming process. That is, the material behaviour during cooling from the forming heat is partly dependent on the state of deformation. The plastic pre-deformation in the austenitic state affects the phase transformation behaviour. In addition, the degree of deformation influences the development of stresses during cooling as a result of material hardening. The purely thermal execution of the study without integrated forming would therefore lead to significantly different results.

The methodology of the research work is shown in Fig. 3. The basis of the studies is an earlier publication of the authors [39], where the resulting residual stresses of hot-formed specimens from two process strategies were investigated with the experimental equipment presented in Sect. 2.1. In the process strategy 1A, it was found that after hot forming with subsequent cooling in water, the manufactured components exhibit a fully hardened martensitic structure and tensile residual stresses on the surface. In strategy 1B, low residual stresses were found on the specimen surface after hot forming with subsequent cooling in atmospheric air. With the motivation outlined in Sect. 1, stating that the induction of compressive residual stresses at the surface can improve component performance, the residual stress states detected on these components are considered undesirable. Instead, two alternative process strategies (2A and $2 \mathrm{~B}$ ) are to be developed, which also produce martensitic and pearlitic specimens, but with near-surface compressive residual stresses.

For this reason, a closer theoretical look at the material phenomena as well as process parameters is intended. The material used is comprehensively characterised as shown in Sect. 2.2.1, and the derived numerical models are validated by means of the experimental results of strategies 1A and 1B [40]. In the next step, 


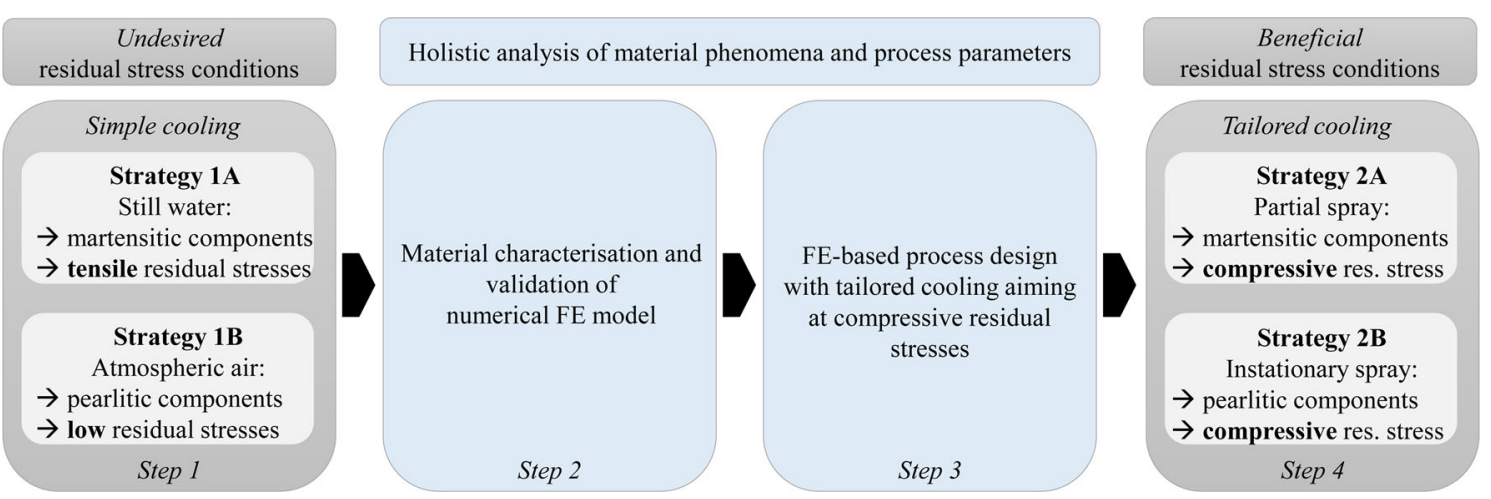

Fig. 3 Methodology of experimental and numerical investigations aiming at compressive residual stresses in the component surface induced by the hot-forming process

Table 1 Chemical composition of the investigated steel alloy AISI 52100

\begin{tabular}{lllllllll}
\hline [wt\%] & $\mathrm{C}$ & $\mathrm{Si}$ & $\mathrm{Mn}$ & $\mathrm{P}$ & $\mathrm{S}$ & $\mathrm{Cr}$ & $\mathrm{Mo}$ & $\mathrm{Fe}$ \\
\hline AISI 52100 & 0.98 & 0.28 & 0.31 & 0.012 & 0.006 & 1.42 & 0.01 & Balance \\
\hline
\end{tabular}

the FE model is employed for process design including tailor-made cooling by water-air spray. For this purpose, the experimental equipment is extended by a spray cooling system, whose heat transfer coefficients are determined according to Sect. 2.2.3. Numerical investigations are conducted to study the interactions between process parameters and material phenomena in order to develop the process strategies $2 \mathrm{~A}$ and $2 \mathrm{~B}$. In these processes, the same components with similar microstructures as in strategies 1A and 1B are produced, aiming at residual compressive stresses on the component surface. These process strategies are regarded as exemplary for introducing compressive stresses, while there may indeed be other possibilities to achieve this goal. The developed strategies are discussed in Sect. 3.1 and experimentally realised in order to verify the numerical results in Sect. 3.2. A summary of the work and an outlook on future research is given in Sect. 4 .

The investigations concern the typical hot-forming steel alloy with the international material number AISI 52100. The chemical composition is specified in Table 1.

\subsection{Experimental procedure}

\subsubsection{Experimental equipment for precision hot forming provided with a spray cooling system}

In the experimental reference process of hot forming, the specimens shown in Fig. 4a are upset by $22 \mathrm{~mm}$ at about $200 \mathrm{~mm} / \mathrm{s}$ between two anvils. The specimen design based on [41] is chosen to generate an inhomogeneous stress state in the material, as it may occur in industrial components. The heating of the specimens takes place in a furnace. After reaching the forming temperature of $1000{ }^{\circ} \mathrm{C}$, a ten-minute holding time is added for soaking. The servo-hydraulic forming simulator DYNSJ5590 is used for hot forming. In order to ensure a quasi-isothermal process, forming takes place inside a thermobox, which allows the temperature to be measured via thermocouples type $\mathrm{K}(\mathrm{NiCr}-\mathrm{Ni})$ during the entire process (Fig. $4 \mathrm{~b})$.

After forming, the specimens are cooled using the varying strategies shown in Fig. 3. More information on the reference process can also be found in the publication [39].

The spray cooling system employed and presented in Fig. 5 works with six circularly arranged twosubstance nozzles of the type XA PR 050 from Bete $\mathrm{GmbH}$. The media water and air are supplied to the nozzles at a pressure of $0.04 \mathrm{MPa}$. This results in a volume flow of water of about $0.2 \mathrm{l} / \mathrm{s}$. The solenoid valves upstream of the nozzles are controlled by the NI-9375 digital I/O module from National Instruments and programmed using the software LabVIEW.

The partial cooling strategy $2 \mathrm{~A}$ is performed with only one active nozzle at a distance of $90 \mathrm{~mm}$ from the specimens' centre and takes place immediately after hot forming for $300 \mathrm{~s}$. The specimen is positioned in a manner that the spray cone impacts approximately $90^{\circ}$ of the circumference on the thick-walled side of the specimen, with MP1 in the centre. 

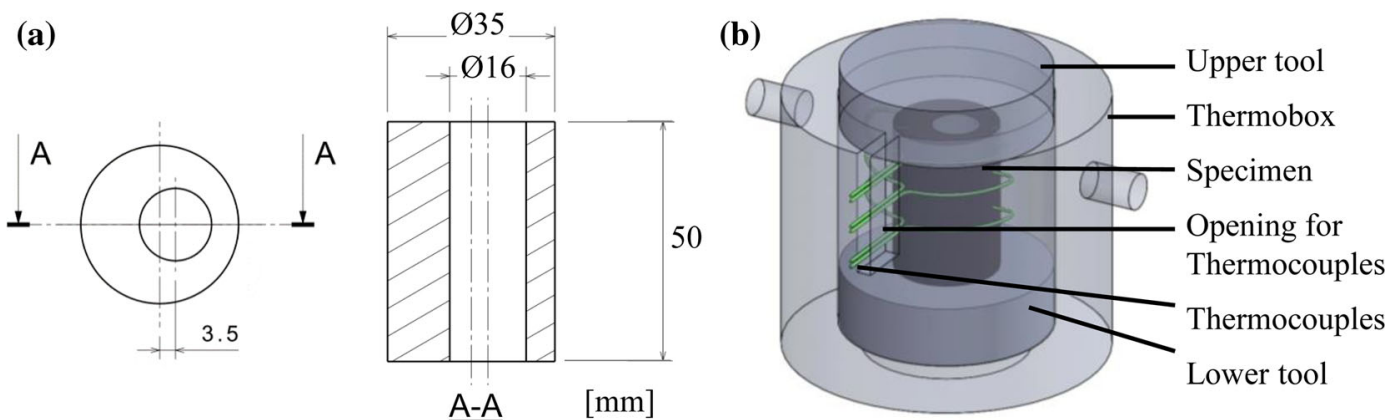

Fig. 4 Shape of the specimens investigated with dimensions in $\mathrm{mm}$ (a) and schematic representation of the specimen prepared with thermocouples in a thermobox (b) [39]

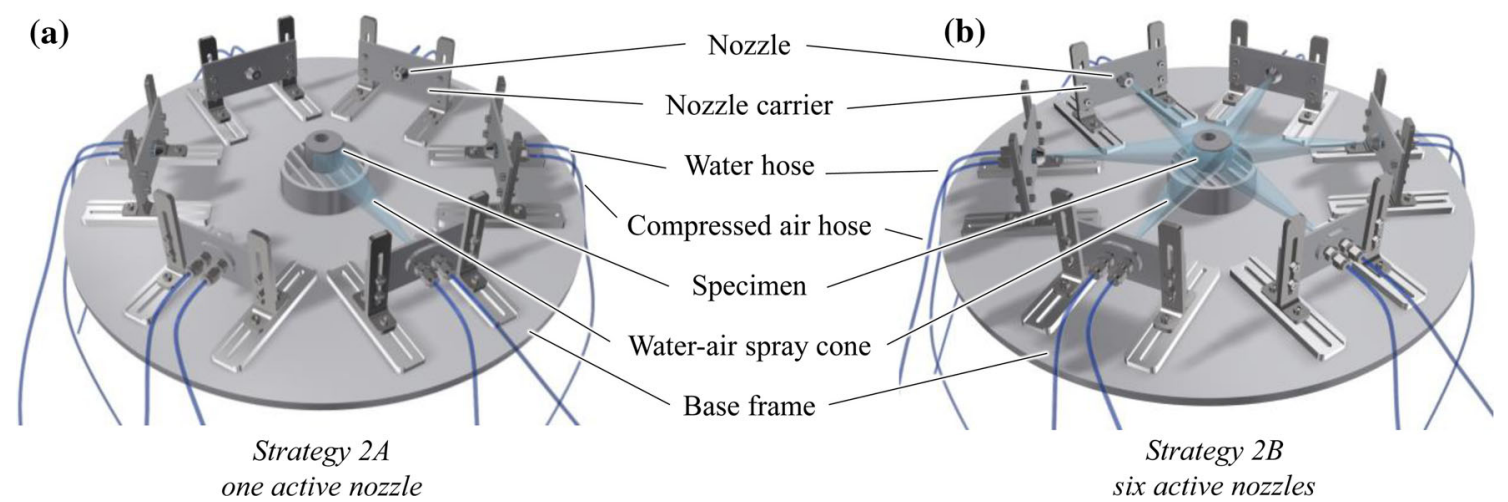

Fig. 5 Water-air spray system for tailored cooling using one active nozzle (a) or six active nozzles (b)

The instationary cooling strategy $2 \mathrm{~B}$ is performed with six active nozzles arranged surrounding the specimen. In this case, the entire circumferential surface of the specimen is exposed to the spray. After forming, the specimens are cooled in air for $300 \mathrm{~s}$ followed by $100 \mathrm{~s}$ spray cooling. The selection of process parameters is made on the basis of numerical analyses and discussed in Sect. 3.1.

Thus, the cooling of strategies $2 \mathrm{~A}$ and $2 \mathrm{~B}$ differs both in terms of spatial and temporal characteristics. In strategy $2 \mathrm{~A}$, the specimen is partially cooled, as only a section of the specimen surface on the thick-walled side is exposed to the spray, whereas in strategy $2 \mathrm{~B}$ the entire specimen surface is exposed to the spray. However, the specimen in strategy 2B is not cooled continuously, but variably over time, as the 300-s cooling in air is followed by further cooling in the spray field. In both strategies, the specimen is cooled until room temperature is reached. Each of the four strategies is carried out three times in order to scientifically and statistically confirm the experimental residual stress results.

\subsubsection{Determination of residual stresses using X-ray diffraction}

The determination of residual stresses is carried out according to the German Standards [42] using $\mathrm{Cr}-\mathrm{K} \alpha$ radiation on the X3000G2 X-ray diffractometer from Stresstech $\mathrm{GmbH}$. The respective measuring point is polished electrolytically in order to avoid influences on the analyses from the layer of scale arising in the hotforming process. The measuring point is defined by a collimator with a diameter of $2 \mathrm{~mm}$. Nine tilting positions of the measuring device are used per measuring point for stress evaluation. Afterwards, the measurements are evaluated with the software XTronic (Stresstech $\mathrm{GmbH}$ ) by means of the $\sin ^{2}$ method. The residual stresses are calculated based on the $\{211\}$ peak of the ferritic lattice. The X-ray elasticity constant $1 / 2 \mathrm{~s}_{2}=5.81^{*} 10^{-6}$ $\mathrm{mm}^{2} \mathrm{~N}^{-1}$ is taken from the tabular data collection of [43].

The measuring points (MP) for determining the residual stresses are located on the surface at mid-height of the specimen, whereby only MP1 and MP6 (Fig. 6b) and further measuring points at the angle $\theta$ on the circumference of the specimen surface (Fig. 6c) are accessible for X-ray examinations. At the measuring points MP2 to MP5 inside of the specimen in addition to MP1 and MP6, metallographic examinations are carried out as described in Sect. 2.1.3. 


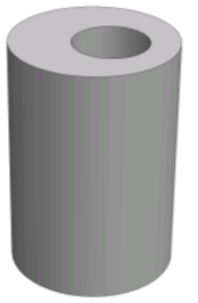

(a) Untreated specimen

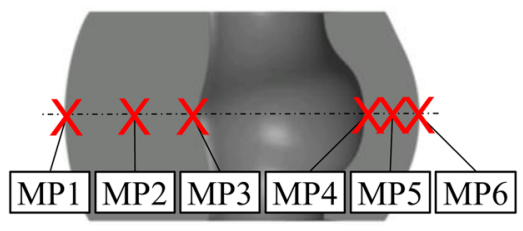

(b) Measuring points (MP) at midheight of the specimen

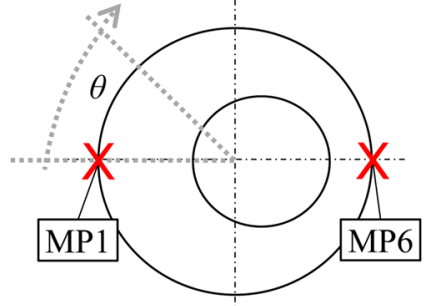

(c) MP on the circumferential surface indicated by the angle $\theta$

Fig. 6 Illustration of the untreated specimen (a), the measuring points MP1 to MP6 at mid-height of the specimen (b) as well as the angle $\theta$ on the circumference of the specimen (c)

\subsubsection{Light microscopy and hardness measurements according to Vickers}

Following the hot-forming tests, one specimen per strategy is cut along its plane of symmetry by wire erosion as shown in Fig. 6b. This allows the preparation of light microscopic images of the microstructure as well as Vickers hardness testing at MP1 to MP6. The hardness tests at the measuring points are carried out after grinding and polishing of the cut surface as HV30 tests according to the German standards DIN EN ISO 6507-1 [44].

\subsubsection{D Optical scanning method}

In order to compare the component geometries resulting from the different thermo-mechanical treatments, $3 \mathrm{D}$ models of the experimental specimen are generated using an optical scanning method. The optical measurements are taken with the ATOS II 400 system from GOM GmbH. In the configuration used, this system provides a camera resolution of $1.3 \mathrm{MP}$ in a measuring volume of $175 \mathrm{~mm} \times 140 \mathrm{~mm} \times 135 \mathrm{~mm}$, corresponding to a measuring point distance of $130 \mu \mathrm{m}$. Using the software Inspect from GOM GmbH, CAD models of the experimental specimens are created by optical scans and the geometries of the differently manufactured components are compared.

\subsection{Numerical procedure}

\subsubsection{Characterisation of the thermo-mechanical-metallurgical material behaviour}

The methods of material characterisation have already been published in earlier works which are referred to in the following. The flow curves for modelling hot-forming processes are determined in uniaxial compression tests on the Gleeble 3800-GTC forming simulator for the temperature range $T_{\mathrm{f}}=900{ }^{\circ} \mathrm{C}$ to $1200{ }^{\circ} \mathrm{C}$ at forming rates from $\dot{\varepsilon}_{\text {eq }}=1 \mathrm{~s}^{-1}$ to $50 \mathrm{~s}^{-1}$ (Fig. 7a) [39]. Based on these experimental data, Origin software is used to determine the parameters of the GMT flow curve model (Eq. 2-1) by means of the least squares method to continuously calculate the yield stress $k_{\mathrm{f}}$ as a function of plastic strain $\varepsilon_{\text {eq }}$, strain rate $\dot{\varepsilon}$ eq, and temperature $T_{\mathrm{f}}$. The parameters were determined as $c_{1}=3113.02 \mathrm{MPa} ; c_{2}=-0.0033{ }^{\circ} \mathrm{C}^{-1} ; n_{1}=5.0507 * 10^{-5}$ ${ }^{\circ} \mathrm{C}^{-1} ; n_{2}=0.109 ; l_{1}=-2.0135 * 10^{-5}{ }^{\circ} \mathrm{C}^{-1} ; l_{2}=0.0024 ; m_{1}=6.6491 * 10^{-4}{ }^{\circ} \mathrm{C}^{-1} ; m_{2}=0.5$.

$$
k_{\mathrm{f}}=c_{1} e^{c_{2} T_{\mathrm{f}}} \varepsilon_{\mathrm{eq}}{ }^{n_{1} T_{\mathrm{f}}+n_{2}} e^{\frac{l_{1} T_{\mathrm{f}}++_{2}}{\varepsilon_{\mathrm{eq}}}} \dot{\varepsilon}_{\mathrm{eq}}^{m_{1} T_{\mathrm{f}}+m_{2}}
$$

The phase transformation behaviour is investigated with and without previous deformation in cooling tests on the Quench and Deformation Dilatometer DIL 805A/D + T. Figure 7b shows the transformation behaviour in a continuous cooling transformation (cct) diagram. For modelling, the cct is converted into a time temperature transformation (ttt) diagram using an experimental numerical approach [45].

In addition, the transformation plastic effect of phase transformations occurring under superimposed loads is investigated. For this purpose, using an experimental-numerical method, the following phase-specific transformation plasticity parameters can be determined as $K_{\mathrm{tr}, \mathrm{m}}=4.85^{*} 10^{-5} \mathrm{MPa}^{-1}$ for the martensitic phase as well as $K_{\mathrm{tr}, \mathrm{p}}=6.17 * 10^{-5} \mathrm{MPa}^{-1}$ for the pearlitic phase [40]. 

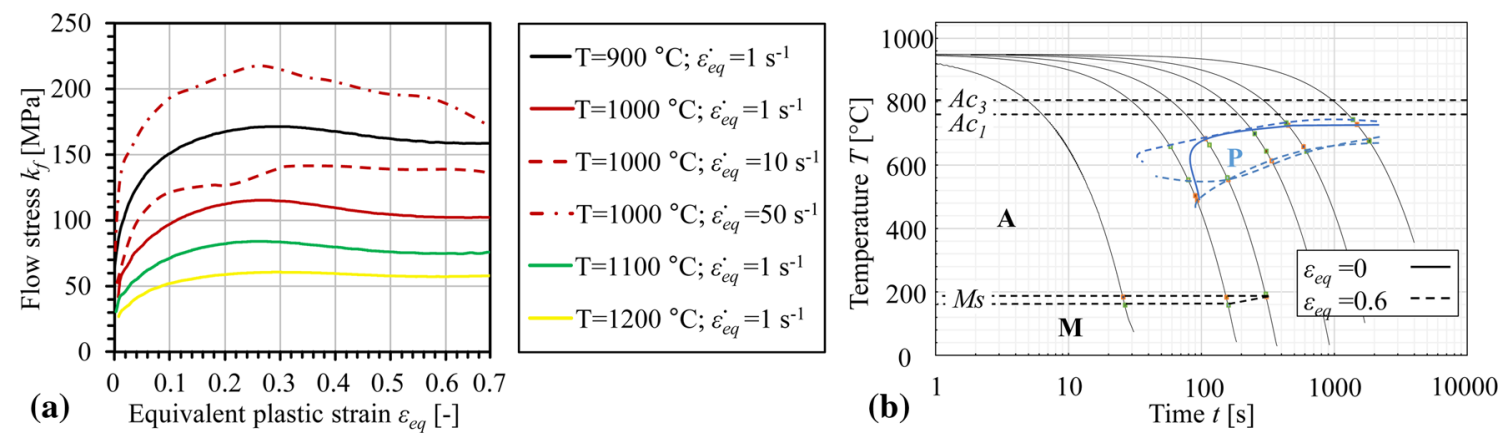

Fig. 7 Flow curves for different temperatures $T_{\mathrm{f}}$ and different strain rates $\dot{\varepsilon}_{\text {eq }}$ determined in upsetting tests by means of the Gleeble 3800-GTC (a) as well as continuous cooling transformation diagram (b) for the material AISI 52100

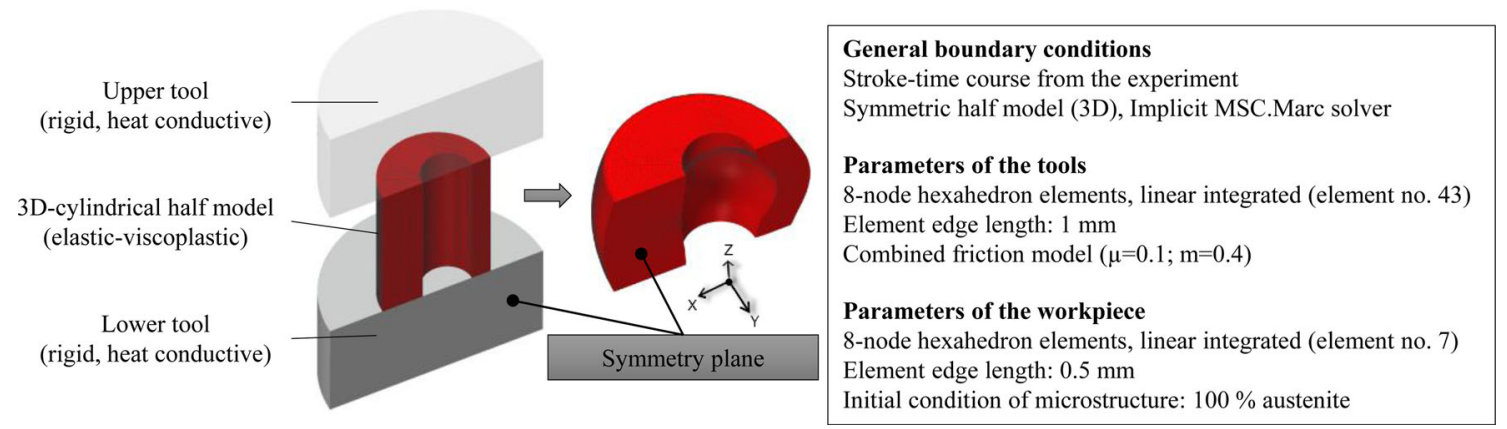

Fig. 8 Design of the investigated FE simulation model with boundary conditions [40]

For a holistic numerical consideration of the hot-forming process chain, it is also necessary to include a variety of other material parameters in the simulation in a phase-specific manner in order to correctly represent the polymorphism of steel. Since an experimental determination of many material parameters for the pure microstructure phase is challenging [46], the thermodynamic calculation software JMatPro [47] is used. By means of this software using empirical equations based on the chemical composition of Table 1, phase-specific and temperature-dependent values for specific heat capacity, thermal conductivity, coefficient of thermal expansion, density, Young's modulus, Poisson ratio, latent heat and hardness are calculated. The data have already been published in tabular form in [39].

\subsubsection{FE model of the hot-forming process}

The simulation model of the reference process of hot forming is created analogous to the experimental process conditions shown in Sect. 2.1.1 in the commercial FE software Simufact.forming v16 and computed with the MSC.Marc solver. The data presented in Sect. 2.2.1 are used to model the material behaviour. The simulation starts at the beginning of the forming process with a thermally expanded specimen geometry at $1000^{\circ} \mathrm{C}$ and the initial condition of a $100 \%$ austenitic microstructure. The tools are considered to be thermally conductive rigid bodies made of the material AISI Inconel 718 (DIN 2.4668) with the specific heat capacity of $435 \mathrm{Jkg}^{-1} \mathrm{~K}^{-1}$ and the thermal conductivity of $11.4 \mathrm{Wm}^{-1} \mathrm{~K}^{-1}$ according to the material supplier's specifications [48]. For contact modelling, the combined Coulomb-Tresca model with the friction coefficient of 0.1 and the friction shear factor of 0.4 were used according to [49]. A schematic representation of the symmetric FE half model and the boundary conditions is shown in Fig. 8.

To represent the different cooling techniques in water, air or with spray as described in Sect. 2.1.1, the surface is exposed to the respective heat-transfer coefficient (HTC) from Sect. 2.2.3. The cooling strategies 2A and B with spray are modelled by the so-called near-field contact function in Simufact.forming, which allows to apply a specific HTC to defined surface areas of the component. The HTC from air to steel is assigned to the remaining areas that are not exposed to the spray. 


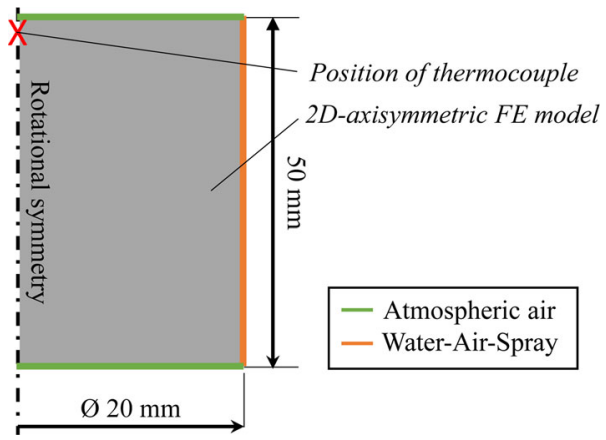

Fig. 9 FE model of the cylindrical specimen for the experimental-numerical HTC determination of the spray

\subsubsection{Identification of the heat-transfer coefficients in the spray cooling system}

The HTC occurring in the different cooling strategies is numerically identified in iterative procedures based on experimental temperature-time data from the different cooling strategies. To determine the HTC during simple cooling between the steel alloy and the media water and air, the temperature curves on the surface of the specimens are measured during the test as described in Sect. 2.1.1. The cooling simulation according to Sect. 2.2.2 is repeated in an automated loop under varying HTC values until a satisfactory solution is obtained by the method of least squares between the calculated temperature-time curves and the experimental temperature-time curves.

In determining the HTC for simple cooling in water and air is on model validation. For the purpose of the numerical design of strategies $2 \mathrm{~A}$ and $\mathrm{B}$, no temperature-time curves are yet available which could be used as a basis for determining the HTC of the spray cooling. In contrast, the HTC from spray cooling should be determined in general and should not be bound to a specific process. Therefore, experimental cooling tests starting at $1000{ }^{\circ} \mathrm{C}$ were performed on cylindrical specimens measuring $\varnothing 40 \mathrm{~mm}$ x $50 \mathrm{~mm}$ using 6 nozzles as described in Sect. 2.1.1. The temperature-time curves are measured using a thermocouple in the middle of the face area in a depth of about $3 \mathrm{~mm}$. Thus, an influence of the heat transfer in the spray field by the supplied thermo-wires is avoided. The rotationally symmetric $2 \mathrm{D}$ model of the cylinder for the experimental-numerical determination of the HTC of the spray is created in Simufact.forming, similar to the model presented in Sect. 2.2.2 and is presented schematically in Fig. 9. The HTC to be determined for the spray is applied to the circumferential surface, while the HTC already determined from the air cooling is applied to the faces of the cylinder. As for the determination of the HTC from water and air cooling, in an automated loop, the HTC for the spray is adjusted until a satisfactory agreement of the temperature curves at the measuring point between experiment and simulation is achieved.

A comparison of the experimentally and numerically determined temperature curves for all cooling strategies to validate the HTC can be found in Sect. 3.1.

The determined HTCs for the different cooling strategies are listed in Table 2. It can be seen directly from the strongly varying HTC that the different cooling strategies cause clearly different temperature profiles in the cooling phase. When cooled in water, the HTC varies significantly over the temperature range of 1000 to $20^{\circ} \mathrm{C}$, as expected, as the various cooling stages of film boiling, bubble boiling and convection are passed through. During the entire cooling process in air, free convection occurs continuously on the component surface, which explains the uniformly low HTCs. Using spray cooling, in contrast, the fine atomisation increases the contact surface between water and component which leads to higher maximum HTCs.

The advantage of this iterative experimental-numerical method for identifying the HTC is that all material parameters from Sect. 2.2.1 are considered. This enables the HTC to be isolated and determined independently of material-specific effects such as the release of latent heat as a result of phase transformations or phase-specific and temperature-dependent specific heat capacity.

\section{Results and discussion}

As described in introduction, tensile residual stresses are found on the surface of martensitic specimens and low compressive residual stresses on pearlitic specimens in previous work produced with process strategies 
Table 2 Numerically identified heat transfer coefficient between steel alloy AISI 52100 depending on cooling strategy as well as temperature

\begin{tabular}{lccc}
\hline Component temperature & Still water & Atmospheric air & Water-air spray \\
\hline 50 & 1398 & 18 & 28,284 \\
100 & 4178 & 18 & 30,560 \\
150 & 8424 & 18 & 27,244 \\
200 & 10,514 & 18 & 17,054 \\
250 & 11,187 & 22 & 15,900 \\
300 & 9823 & 28 & 9399 \\
350 & 8027 & 25 & 7553 \\
400 & 7359 & 21 & 6874 \\
450 & 7132 & 19 & 6337 \\
500 & 6325 & 12 & 5137 \\
550 & 5371 & 19 & 4249 \\
600 & 6337 & 34 & 5130 \\
650 & 6575 & 46 & 4901 \\
700 & 6326 & 58 & 4755 \\
750 & 4327 & 78 & 1134 \\
800 & 1753 & 103 & 563 \\
900 & 864 & 72 & 391 \\
\hline
\end{tabular}

Heat transfer coefficient $\left[\mathrm{Wm}^{-2} \mathrm{~K}^{-1}\right]$ between steel alloy AISI 52100 and

$1 \mathrm{~A}$ and $1 \mathrm{~B}$ using simple cooling in water or air. The focus of the present work is on a targeted change of the tensile residual stresses into compressive residual stresses by modifying the process. Only the residual stresses should be changed, and the final component geometry and the resulting microstructure should be similar to those of the reference processes with water or air cooling. This ensures that the change in residual stresses is only due to the adapted process and not to changed material properties.

As Sect. 1 shows, research exists about common rules for how residual stresses in undeformed cylindrical specimens are affected by martensite start temperature, cylinder diameter or cooling media. These rules lose their validity if no cylindrical geometries as well as materials with deformation gradients are considered. On the one hand, an asymmetric specimen geometry is used here, which changes the temperature gradients and the development of the stresses compared to a simple cylinder. On the other hand, the local distribution of the equivalent plastic strains must also be taken into account. In the considered strategies $(1 \mathrm{~A}, 2 \mathrm{~A}, 1 \mathrm{~B}, 2 \mathrm{~B})$, the same forming parameters of $22 \mathrm{~mm}$ upsetting at $200 \mathrm{~mm} / \mathrm{s}$ and $1000{ }^{\circ} \mathrm{C}$ are applied, while the cooling parameters are different. Therefore, the distribution of the equivalent plastic strains is the same in each strategy. During cooling, the already present equivalent plastic strains influence the local stress development as a result of hardening, depending on the other influencing parameters such as thermal and transformation-induced strains. This shows that it is difficult to apply general rules for the modification of the residual stress state.

For this reason, several FE studies are carried out in which the interactions between the temperature profile and the resulting residual stresses on the previously formed specimens are investigated. The temporal and spatial characteristics of the cooling via spray are varied until a suitable process strategy for the generation of compressive residual stresses is found. As a result, the strategies $2 \mathrm{~A}$ and $2 \mathrm{~B}$ are suitable process variants to achieve this goal.

In strategy $2 \mathrm{~A}$, as in strategy $1 \mathrm{~A}$, hardened martensitic specimens are produced, except that the compressive residual stresses are generated at the surface. This is achieved by partial cooling of the specimen with one active nozzle directed at the thick-walled side of the specimen, as described in Sect. 2.1.1. Section 3.1.1 describes how the modified temporal sequence of thermal, transformation-induced and transformation plastic strains is mainly responsible for the resulting residual stresses.

In strategy $2 \mathrm{~B}$, the aim is to produce compressive residual stresses in the pearlitic specimen. For this purpose, strategy $2 \mathrm{~B}$ is designed to start with slow cooling in air until the perlitic transformation is complete. Based on the cct diagram for the deformed material from Fig. 7b, the duration of air cooling aiming at perlitic transformation is chosen to be $300 \mathrm{~s}$. After a $100 \%$ pearlitic structure is present, martensite formation can no longer occur, even if the critical cooling rate is exceeded. This is exploited in strategy $2 \mathrm{~B}$ to generate residual compressive stresses in the specimen surface. For this purpose, the spray cooling is activated from 300-s cooling time onwards, with the aim of rapidly cooling the specimen surface, which leads to plastification of the 
material. As a result of the thermal contraction of the material core at the end of cooling, residual compressive stresses develop on the specimen surface.

In Sect. 3.2 the process strategies presented are experimentally realised according to Sect. 2.1 and investigated regarding the residual stresses, Vickers hardness, geometric deviation and microstructure. The aim of the investigations is on the one hand to evaluate the prognosis accuracy of the simulation models regarding the residual stress state. On the other hand, the investigations are to prove that it is possible to vary the residual stress state in hot-formed specimens by means of different tailored cooling strategies, while the geometry and the microstructure remain the same. In Sect. 3.2.1, the temperature boundary conditions of the different strategies are first validated, followed by the comparison of experimental and numerical results for the modification of residual stresses in martensitic specimens in Sect. 3.2.2 and in pearlitic specimens in Sect. 3.2.3.

\subsection{Numerical investigations on process strategies aiming at compressive residual stress development}

\subsubsection{Residual stresses in fully hardened components using strategy $1 \mathrm{~A}$ as well as $2 \mathrm{~A}$}

First, strategy 1A is investigated, which involves simple cooling of the specimen in still water after forming. In order to explain the thermal, metallurgical and mechanical phenomena in the material during cooling, the timedependent curves of temperature, cooling rate, martensitic phase fraction and tangential residual stresses at MP1 and MP6 are shown in the left column of Fig. 10. In the right column, a contour plot representing the local manifestation of each state variable in the half section of the specimen at selected stages of the cooling process is illustrated. After a process time of $7.2 \mathrm{~s}$, a maximum tensile stress is present at MP1, while a compressive stress is present at MP6. In the material core of the thick-walled side, on the other hand, compressive stresses are present, and tensile stresses in the core of the thin-walled side. On the thick-walled side, a higher cooling rate occurs at the surface than inside the specimen at this stage, resulting in the formation of tensile stresses at the surface due to plasticising following thermal contraction. In contrast, the thin-walled side has stored less energy due to its lower mass, which explains why it has already cooled down to lower temperatures than the thick-walled side. The cooling of the surface on this side has already progressed so far that the maximum cooling rate is shifted into the material core, and thus, compressive stresses are present at MP6 due to thermal contraction in the core. In the further course of cooling, the effects of thermal contraction are superimposed by volume expansion due to the transformation from austenite to martensite. At a process time of $16.8 \mathrm{~s}$, there is a maximum of compressive stress at MP1, while tensile stress occurs in the core. The martensitic phase transformation is almost completed on the surface of the specimen, while an austenitic phase is still present in the core. The martensitic material regions with higher specific volume thus cause a strain gradient which leads to the observed compressive stress maximum. The effect is intensified by the stronger thermal contraction in the core compared to the sample surface at this stage. At MP6, on the other hand, there is a tensile stress maximum, since the martensite transformation has already taken place in the specimen core.

The volume expansion in the core has generated a strain gradient, which caused a sign reversal of the stress state. This reversal in the sign of stress as a result of volume expansion due to martensite transformation in the specimen core can also be observed at MP1, starting from a process time of $16.8 \mathrm{~s}$. At the end of the martensitic phase transformation, MP1 and MP6 contain about 85 vol. \% martensite and 15 vol. \% retained austenite.

Finally, until the cooling process is completed by reaching $20^{\circ} \mathrm{C}$, a slight decrease in tensile stresses appears at MP1 as well as at MP6, which can be explained by the thermal contraction in the specimen core on both sides. After equalisation of the thermal, metallurgical and mechanical inhomogeneities, $\sigma_{\mathrm{t}}=338 \mathrm{MPa}$ at MP1 and $\sigma_{\mathrm{t}}=157 \mathrm{MPa}$ at MP6, remain in the specimen as residual stresses.

Based on the experimental and numerical observations of the residual stress developments in the strategy $1 \mathrm{~A}$, an alternative strategy is to be developed, whereby in the martensitic microstructure instead of the tensile residual stresses compressive residual stresses are present in near-surface areas. For this purpose, several FE studies are carried out in which the interactions between the temperature profile and the resulting residual stresses are investigated. The analysis of the strategy 2A presented in Fig. 11 is therefore representative as an exemplary process for demonstrating the feasibility to essentially influence the stress state in the component by intelligent cooling.

In this strategy, the specimen is partially exposed to the air-water spray through only one active nozzle pointing at MP1 on an area of about $90^{\circ}$ of the circumference as shown in Fig. 5a. Cooling starts immediately after hot forming and is performed continuously for $300 \mathrm{~s}$. In the first stage, the specimen rapidly cools down on the surface exposed to the spray, which leads to an incipient martensite transformation in MP1 after $29 \mathrm{~s}$ of 


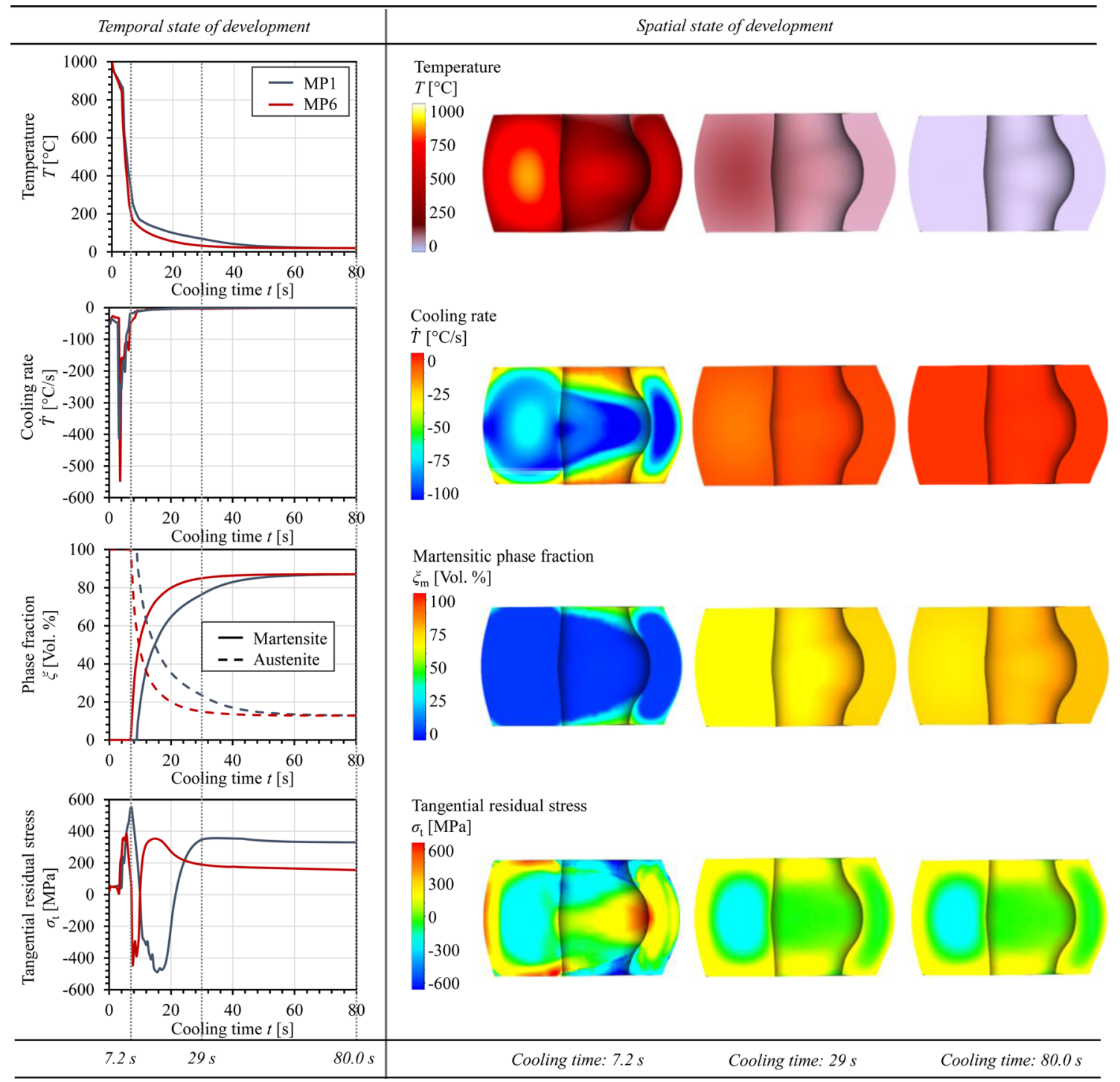

Fig. 10 Temporal and spatial development of residual stresses arising from process strategy 1A during simple cooling in water

process time. The martensite transformation causes a local increase in yield strength in the specimen surface in relation to the yield strength of the austenitic phases. Therefore, very high stresses can be developed in the martensitic phase before the stress relief by plastic deformation occurs. This leads to high tensile stresses of almost $\sigma_{\mathrm{t}}=1000 \mathrm{MPa}$ at MP1 due to thermal contraction at this stage. For comparison, it can be seen in Fig. 10 that at this process time of $29 \mathrm{~s}$ with strategy 1A, the specimen at MP1 and MP6 is already cooled to below $100{ }^{\circ} \mathrm{C}$ and the martensite transformation is almost complete. The faster cooling results from the entire surface being exposed to the cooling medium water, while the slower cooling in strategy $2 \mathrm{~A}$ results from the one-sided spray cooling. Despite the slower cooling in strategy $2 \mathrm{~A}$, however, the critical cooling rate is exceeded and diffusionless martensite transformation occurs. In the further course of cooling, the martensite transformation continues at MP1; the strains caused by the higher specific volume of the martensitic phase leading to a reversal of the sign of stress and now at the time of $38.4 \mathrm{~s}$ approximately $\sigma_{\mathrm{t}}=-1000 \mathrm{MPa}$ are present at MP1. Up to this point in time, only slight changes in stresses have occurred at MP6 in the not yet transformed austenitic phase due to the significantly slower cooling.

Starting at $39.4 \mathrm{~s}$, the martensite transformation now continues from MP1 towards MP6 over the circumference of the specimen. The resulting volume expansion on the thick-walled side of the specimen core slightly reduces compressive stresses at MP1. However, due to thermal contraction and volume expansion as a result of 


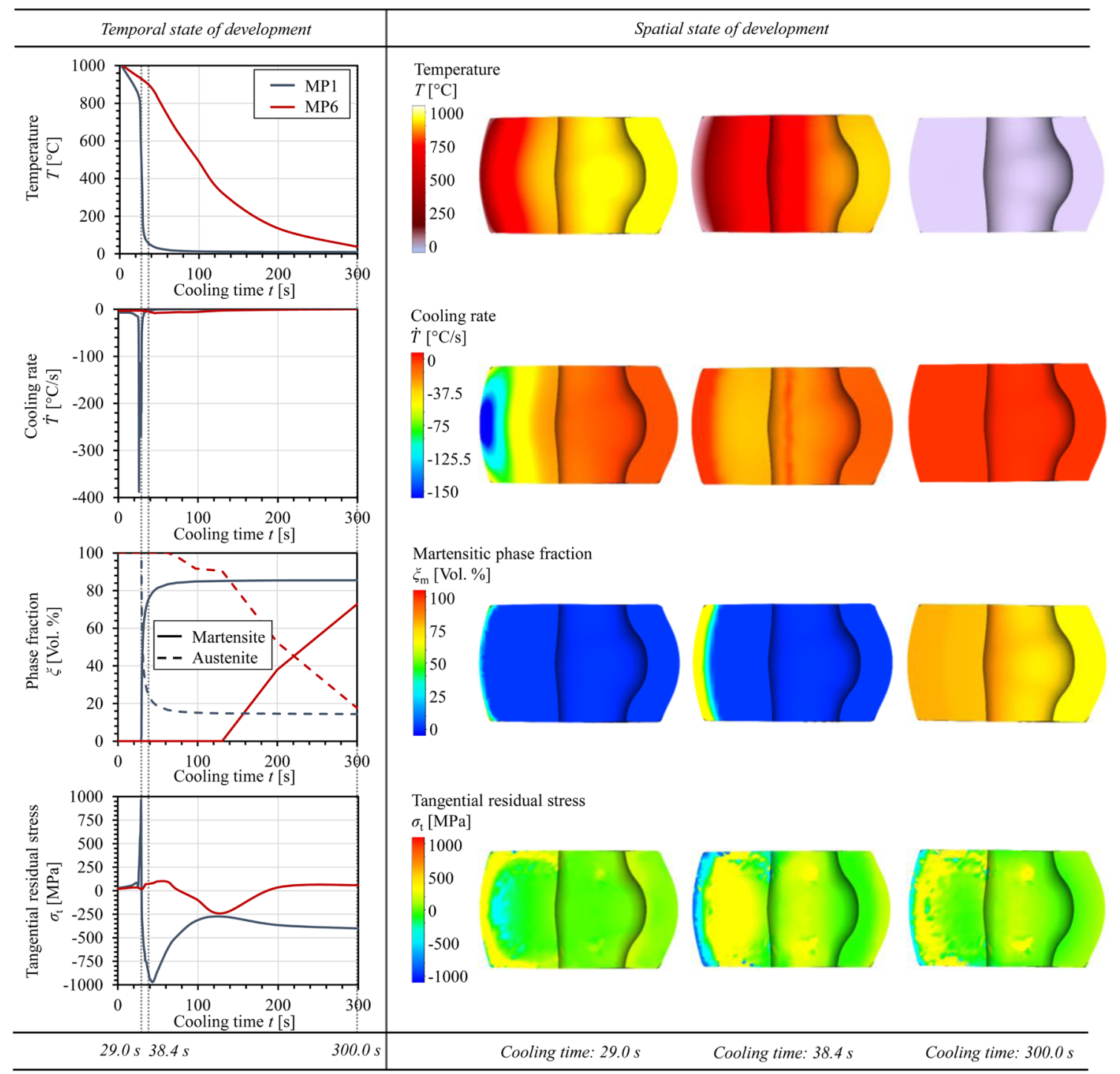

Fig. 11 Temporal and spatial development of residual stresses arising from process strategy 2A during tailored cooling

the martensite transformation on the circumference of the specimen, the stress at MP1 remains in the negative range. Starting at a process time of about $110 \mathrm{~s}$, enough energy is removed from the thin-walled side of the specimen to reach the Ms temperature as well. At this point in time, compressive stresses are present at MP6 due to the preceding volume expansion resulting from martensite transformation in the neighbouring regions. The phase transformation at MP6 therefore takes place under superimposed compressive stress, which, in accordance with the transformation plastic effect, significantly weakens volume expansion in circumferential direction. It is remarkable that the simulation predicts a lower martensite content at MP6 ( $\left.\xi_{\mathrm{m}}=72 \mathrm{Vol} . \%\right)$ than at MP1 $\left(\xi_{\mathrm{m}}=85 \mathrm{Vol} . \%\right)$ due to the lower cooling rate. Instead, a microstructure with $10 \%$ pearlitic content is calculated for the material at MP6, which develops during the slow cooling at this side of the specimen. Accordingly, a slightly decreasing austenite content can be seen between 66 and 109-s process time at MP6 in Fig. 11.

Furthermore, as the material sections at MP6 are the last to cool down, adjacent to the already cold regions with significantly higher yield strength, strains leading to tensile stresses occur due to thermal contraction. After equalisation of thermal, metallurgical and mechanical inhomogeneities, $\sigma_{\mathrm{t}}=-429 \mathrm{MPa}$ at MP1 and $\sigma_{\mathrm{t}}$ $=65 \mathrm{MPa}$ at MP6 remain in the specimen as residual stresses. 


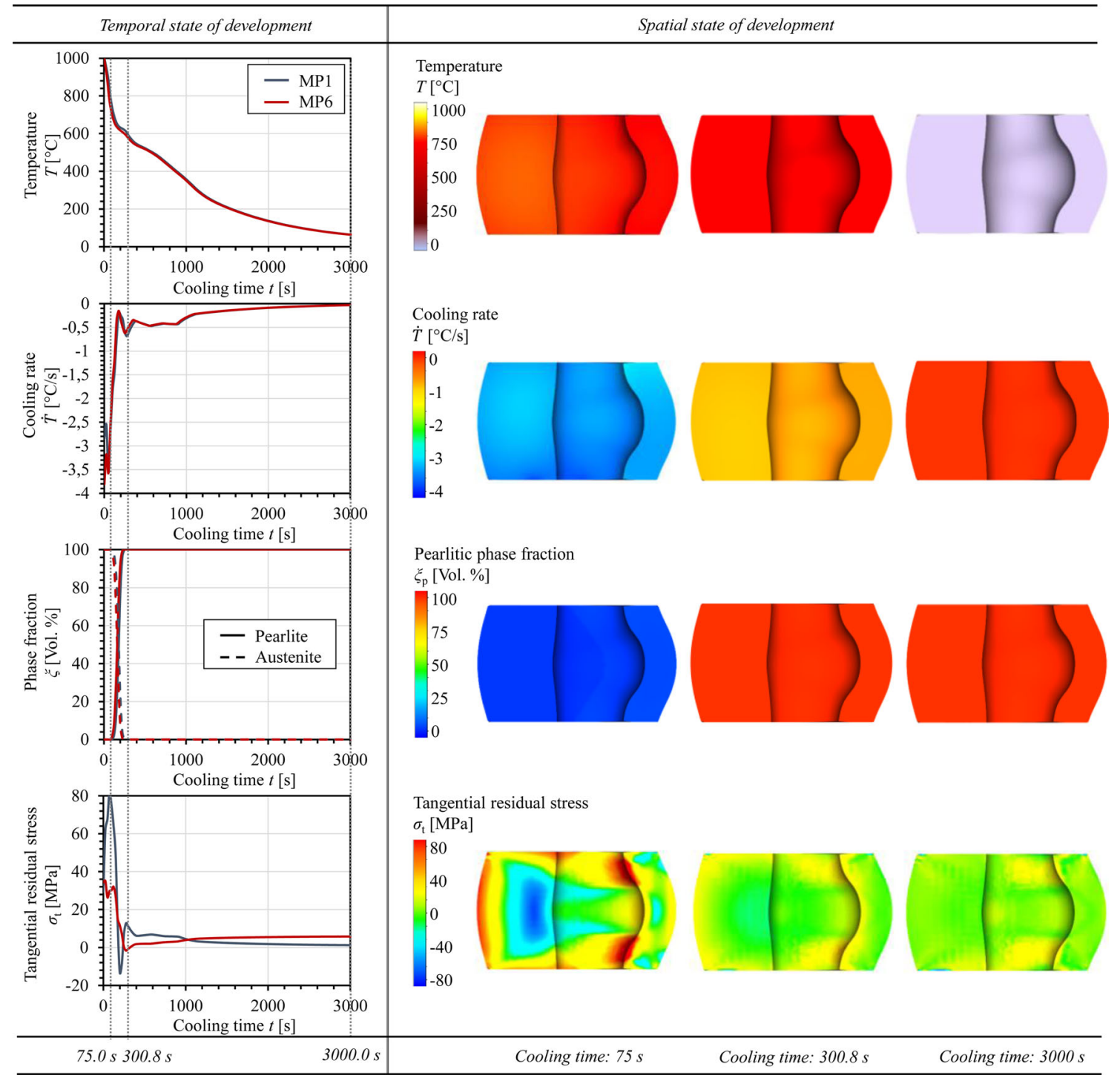

Fig. 12 Temporal and spatial development of residual stresses arising from process strategy 1B during simple cooling in atmospheric air

\subsubsection{Residual stresses in pearlitic components using strategy $1 B$ as well as $2 B$}

In this chapter the possibility of generating compressive stresses in the pearlitic material phase of AISI 52100 is considered. First, strategy $1 \mathrm{~B}$ is investigated, which involves simple cooling of the specimen in atmospheric air after forming. For this process, the temporal as well as spatial development of the stresses at certain stages is shown in Fig. 12 as before.

In this strategy, the cooling from forming temperature to room temperature takes about $3000 \mathrm{~s}$, so that largely homogeneous cooling rates of approximately $3.5{ }^{\circ} \mathrm{C} / \mathrm{s}$ maximum occur over the entire cross section of the specimen at all stages. The tensile stress maximum after $75 \mathrm{~s}$ process time is caused by the thermal contraction of the material on the specimen surface. After 200 s process time, however, the temperature gradient between the surface and the core of the specimen is balanced. This is followed by a relaxation of the tensile stresses. The relatively simultaneous pearlitic phase transformation over the specimen cross section leads to a volume expansion, which explains the low compressive stresses. Finally, residual stresses of $\sigma_{\mathrm{t}}=-11 \mathrm{MPa}$ at MP1 and $\sigma_{\mathrm{t}}=1$ after $3000 \mathrm{~s}$, respectively. 


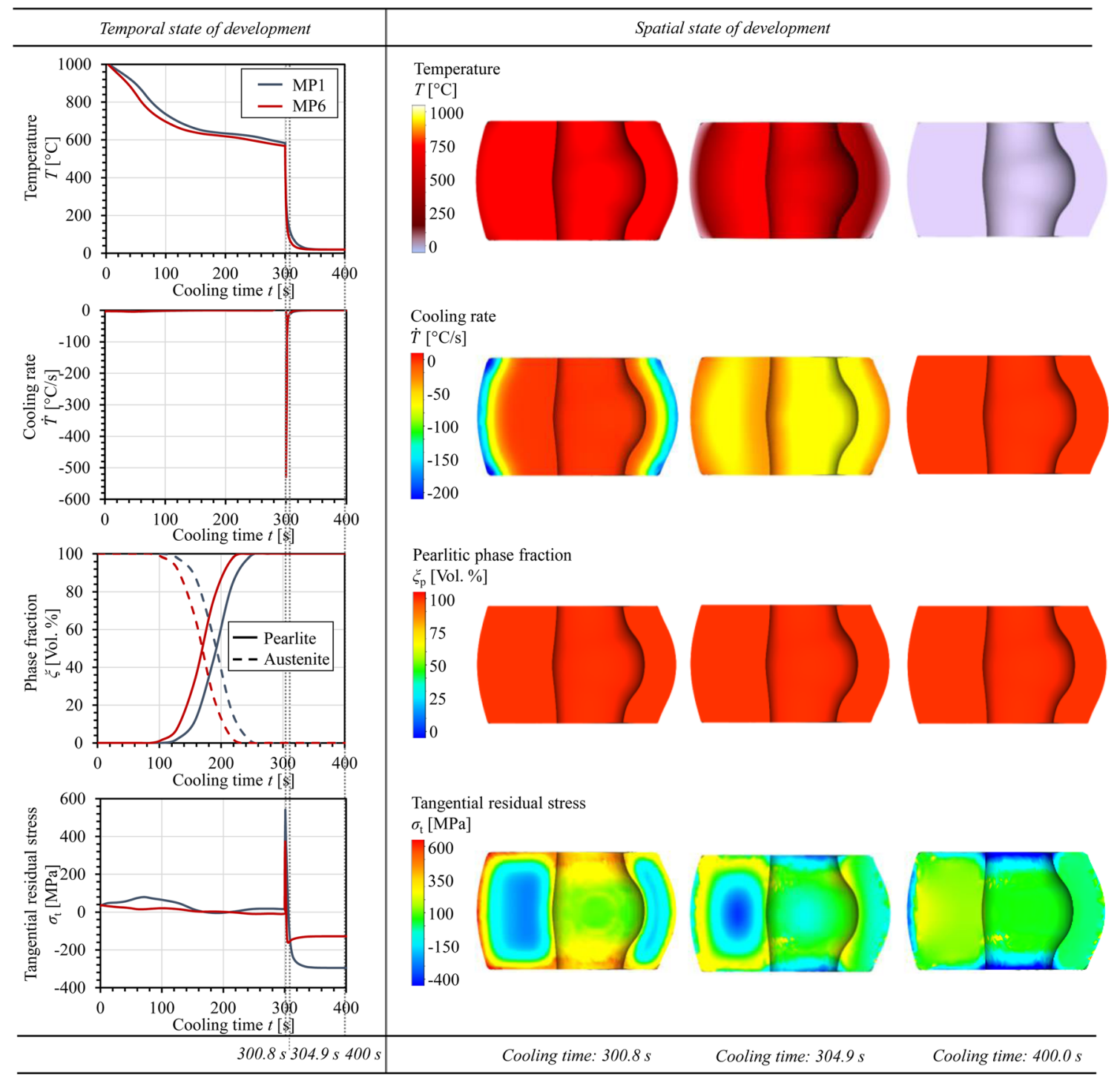

Fig. 13 Temporal and spatial development of residual stresses arising from process strategy $2 \mathrm{~B}$ during tailored cooling

With the aim of generating near-surface compressive residual stresses in the pearlitic specimens, strategy 2B is investigated, for which the numerical results are presented in Fig. 13.

As described in Sect. 2, in this strategy the specimen is slowly cooled in air for $300 \mathrm{~s}$ exactly like in strategy 1B. But in strategy 2B starting from $300 \mathrm{~s}$, the specimen is rapidly quenched in the spray field using six active nozzles as shown in Fig. 5b. After cooling in air, the pearlitic phase transformation is already completely finished and a homogeneous structure is present in the specimen. At the onset of rapid cooling from 300-s process time, very high cooling rates of up to $500{ }^{\circ} \mathrm{C} / \mathrm{s}$ are present on the specimen surface. Shortly afterwards, thermal contraction at $300.8 \mathrm{~s}$ results in a maximum tensile stress at MP1 and MP6. As a result of the high strains, the material at the surface of the specimen is plasticised. In contrast, in strategy $1 \mathrm{~B}$, at this process time the slow cooling in air continues. Therefore, the specimen has a homogeneous temperature distribution over the entire cross section, which explains minor resulting residual stresses caused by inhomogeneous plastification. In strategy $2 \mathrm{~B}$, at $304.9 \mathrm{~s}$, the maximum cooling rate shifts into the specimen core on the thick-walled side as well as on the thin-walled side. Now the material core experiences a higher thermal contraction than at MP1 and MP6 on the surface. Because of the preceding plastic strains at the surface, the thermal contraction in the specimen core now results in a reversal of the stress sign. After the inhomogeneous thermal strains have been equalised, residual stresses of $\sigma_{\mathrm{t}}=-297 \mathrm{MPa}$ and $\sigma_{\mathrm{t}}=-130 \mathrm{MPa}$ remain at MP1 and MP6. 
(a)

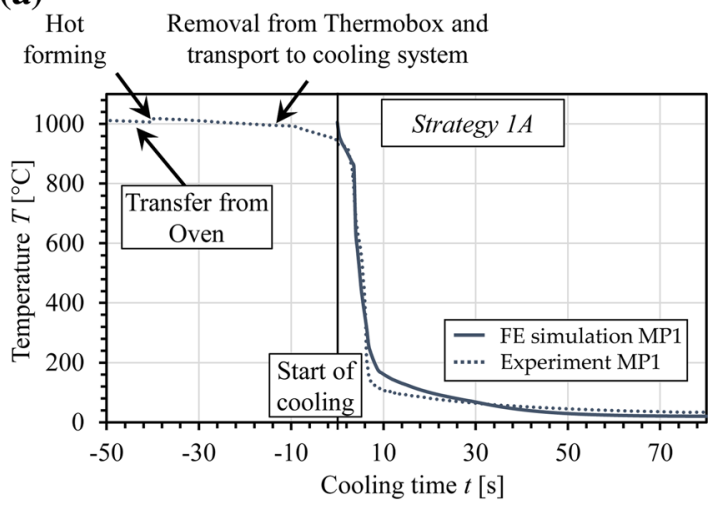

(c)

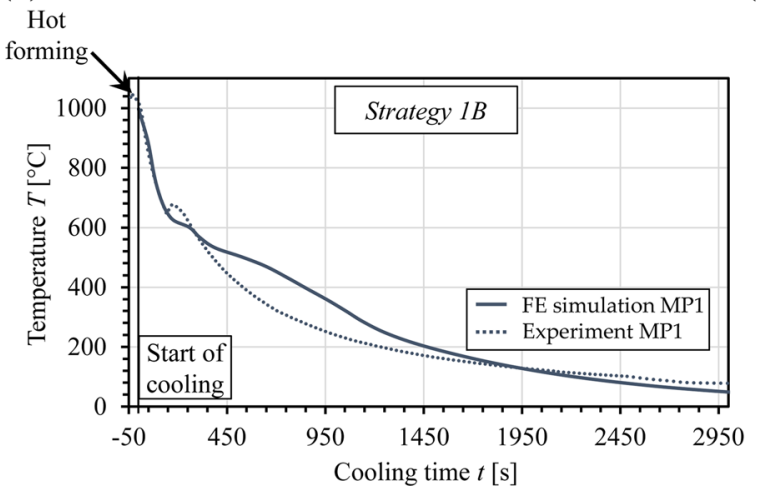

(b)

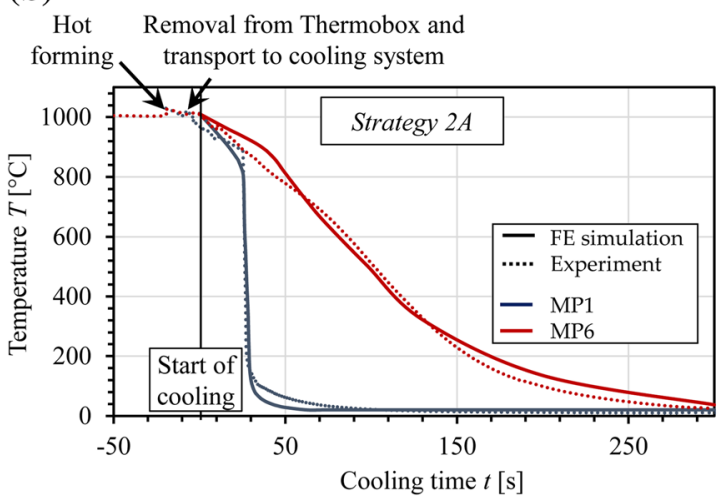

(d)

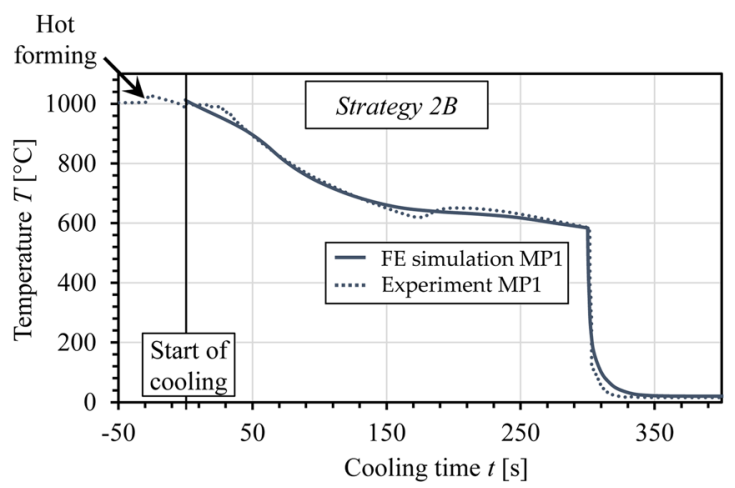

Fig. 14 Comparison of the temperature developments from the numerical and experimental investigations in the strategy $1 \mathrm{~A}$ (a), $2 \mathrm{~A}(\mathbf{b}), 1 \mathrm{~B}$ (c) as well as 2B (d),

In the two modified process variants $2 \mathrm{~A}$ and $2 \mathrm{~B}$, the thermo-mechanical-metallurgical influencing factors of the elastic, plastic, thermal, transformation-induced and transformation-plasticity effects are used to different extents to influence the residual stresses. In strategy $2 \mathrm{~A}$, the focus is on the temporal development of the martensite front, with the transformation-induced strains occurring in the form of martensitic volume expansion. In addition, the thermal strains occur in the form of thermal contraction due to the one-sided cooling of the thick-walled side by the spray. Superimposed on this, the transformation plastic effect, again influenced by the prevailing stresses, affects the extent of the martensitic volume expansion. In sum, these effects lead to local plasticisation of the material at certain times, which generates the plastic strains and the final residual stresses.

In contrast, the transformation-induced and transformation-plastic strains have only a minor influence on the residual stresses formed in strategy $2 \mathrm{~B}$. Primarily responsible for the compressive residual stresses formed here is the inhomogeneous thermal contraction, which causes plastic strains during rapid cooling of the specimen surface. With the thermal contraction of the specimen core at the end of cooling, the previously expanded and now cooled surface areas are contracted, which causes the residual compressive stresses.

\subsection{Experimental application of the numerically designed process strategies}

\subsubsection{Validation of the temperature boundary conditions for the different cooling strategies}

To validate the HTC presented in Sect. 2.2.3, a comparison of the temperature-time curves during cooling from the experiments and simulations is shown in Fig. 14 for each of the different cooling strategies.

In the course of the investigations, it is found that the temperature-time curves measured in the experiments could be replicated well in the different cooling strategies during cooling in water, air or spray. The shape of the temperature-time curve during continuous cooling is therefore always very similar. However, when carrying out the experiments, slightly varying temperatures occur after forming, respectively, at the start of the cooling 
process. Using Fig. 14, the influences on the temperatures are demonstrated on the basis of the temperature curve beginning $50 \mathrm{~s}$ before the start of the cooling process at $0 \mathrm{~s}$. About $50 \mathrm{~s}$ before the start of cooling, all experiments begin with the removal of the thermobox including the specimens from the oven. When the specimens are taken out of the oven, the temperature is always between $1000{ }^{\circ} \mathrm{C}$ and $1010{ }^{\circ} \mathrm{C}$, as the oven is set to $1010{ }^{\circ} \mathrm{C}$ for faster heating of the specimens. By using the thermobox, the temperature decreases only slightly during the transfer time from the furnace to the forming simulator. This ensures that the forming starts at $994^{\circ} \mathrm{C}$ in average with a minor standard deviation of $19^{\circ} \mathrm{C}$ at MP1 for instance. The forming of the specimen is indicated by a jump in the temperature curves by an average of $\Delta T=11^{\circ} \mathrm{C}$ as a result of heat release due to plastic deformation at both measuring points. Directly after forming, the specimen is removed from the thermobox and transferred to the cooling medium. The removal of the specimen from the thermobox and its transfer to the cooling medium take varying time periods in the experiments, as this procedure is not machine-made, but carried out by technical staff with the utmost care due to the high temperatures. During these time periods, the cooling of the specimens takes on differing extents. For MP1, the average temperature at the beginning of cooling in the experiment is determined to be $946{ }^{\circ} \mathrm{C}$ with a standard deviation of $42{ }^{\circ} \mathrm{C}$. Since the experiments are repeated three times for each process strategy and the forming process described above is the same for each case, the values given are the mean of 12 experiments.

In the simulations, cooling starts immediately after forming. In other words, related to the time line in Fig. 14, forming starts at $-0.11 \mathrm{~s}$. Thereby a temperature of $T=1013{ }^{\circ} \mathrm{C}$ is calculated for MP1 and $T=$ $1011{ }^{\circ} \mathrm{C}$ for MP6 due to the heat release as a result of the forming process. This means that at the start of cooling there is a difference of $67^{\circ} \mathrm{C}$ at MP1 between the temperature from simulations and experiments. However, this initial temperature difference is balanced out quickly in the further course of cooling. The fluctuating temperature at the start of cooling is supposed to be of secondary importance for the development of residual stresses. Instead, variations in the austenitic microstructure due to static recrystallisation, which can be altered by varying holding times after forming, respectively, before cooling, influence the development of residual stresses. However, since the temporal fluctuations of the process flow are in the range of seconds, these influences should be marginal.

As Fig. 14 shows, in each case, the temperature curves can be predicted well by the simulation. When cooling in water in strategy $1 \mathrm{~A}$, the entire specimen surface cools very quickly at the same time. Figure 14a exemplarily shows the temperature curves of MP1 from experiment and simulation. In strategy $2 \mathrm{~A}$, in contrast, rapid cooling first takes place at MP1 as a result of the spray cooling, while the specimen cools more slowly at MP6, which is not exposed to the spray (Fig. 14b). In the case of cooling in air in strategy 1B, the entire specimen cools down uniformly, whereby Fig. 14c shows a comparison of the temperature curves from experiment and simulation at MP1. In strategy 2B, the specimen surface also undergoes slow cooling in air at all positions simultaneously for $300 \mathrm{~s}$ and thereafter rapid cooling in the spray, whereby Fig. 14d shows the comparison of the temperature curves at MP1.

With the comparison of the temperature boundary conditions, it can be shown on the one hand that the FE models are able to simulate the cooling well by means of the implemented HTC values. On the other hand, it is evident that the experiments are only subject to minor fluctuations in the temperature curve due to the use of the thermobox. This makes the process suitable for the scientific investigation of the influences from the cooling strategy on the residual stresses.

\subsubsection{Experimentally induced residual stresses in martensitic components using strategy $1 \mathrm{~A}$ as well as $2 \mathrm{~A}$}

The calculated as well as experimentally determined residual stresses on the circumference of the specimens from strategy 1A and 2A are plotted in Fig. 15a with respect to the geometric angle $\theta$.

On the thick-walled side, starting from the angle $\theta=0$ at MP1 up to $\theta=45^{\circ}$, average compressive stresses of $\sigma_{\mathrm{t}}=-407 \mathrm{MPa}$, respectively, $\sigma_{\mathrm{t}}=-223 \mathrm{MPa}$ were generated experimentally with strategy $2 \mathrm{~A}$ as predicted in the simulation. Thus, residual stresses at these positions are significantly modified considering the tensile residual stresses of $\sigma_{\mathrm{t}}=216 \mathrm{MPa}$ for $\theta=0^{\circ}$ and $\sigma_{\mathrm{t}}=146 \mathrm{MPa}$ for $\theta=45^{\circ}$ in average, which arise from simple cooling in strategy $1 \mathrm{~A}$. Starting at $\theta=90^{\circ}$, both strategies generate tensile stresses. Thus, as predicted by numerical analyses, the experimental results show that strategy $2 \mathrm{~A}$ is suitable for the generation of residual compressive stresses at least at positions $\theta=0^{\circ}$ to $\theta=45^{\circ}$.

In the experiments, the residual stresses are generated reproducibly with a maximum standard deviation of $36 \mathrm{MPa}$ in strategy $1 \mathrm{~A}$ and with $68 \mathrm{MPa}$ in strategy $2 \mathrm{~A}$, as shown by the error indicators in Fig. 15.

Comparing the experimental and numerical results, it is noticeable that the residual stresses from strategy $2 \mathrm{~A}$ are overestimated by the simulation. It is assumed that this overestimation of residual stresses results from 

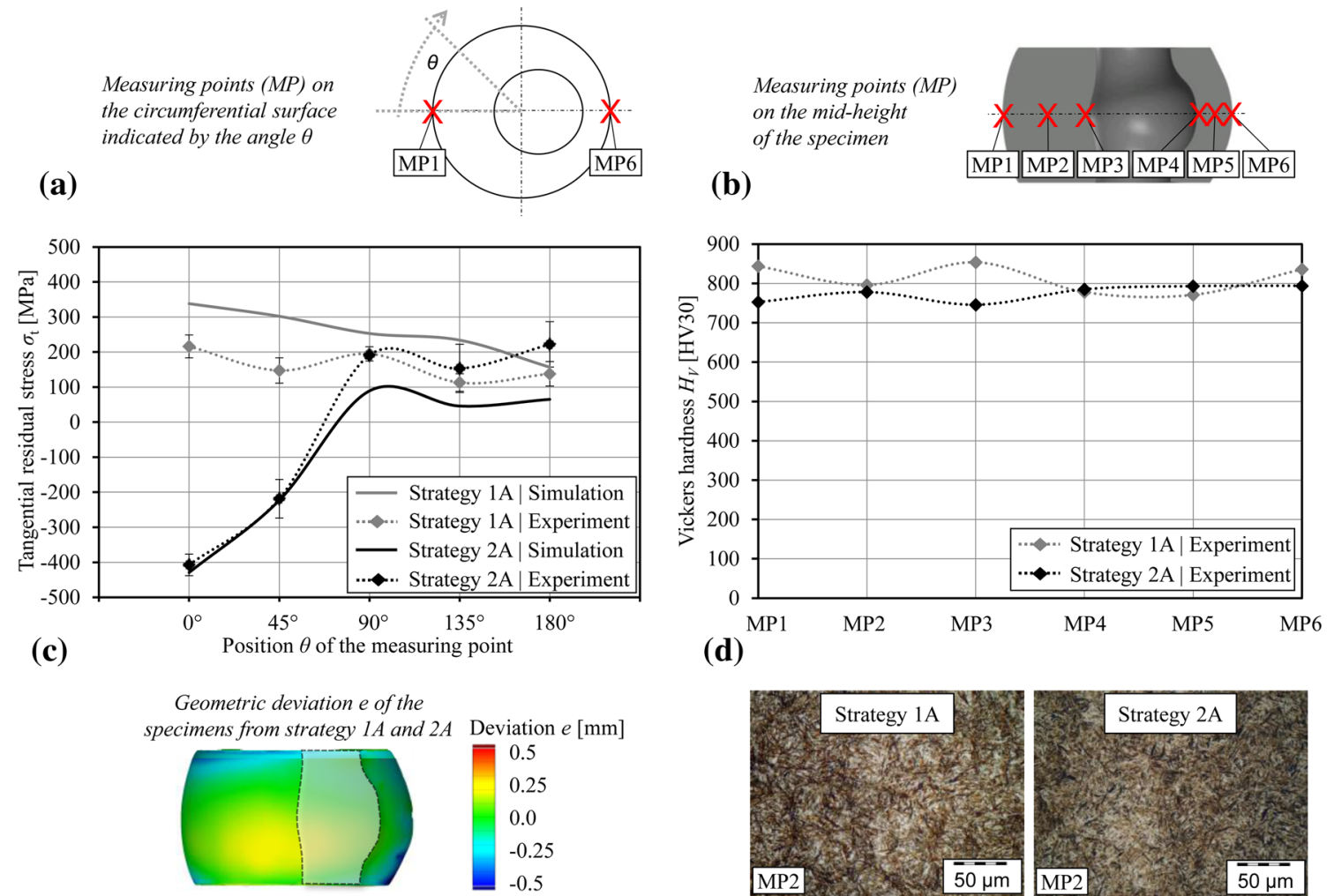

Fig. 15 Comparison of the specimens processed by strategies $1 \mathrm{~A}$ and $2 \mathrm{~A}$ with regard to residual stresses from experiments and simulations (a), Vickers hardness (b), geometric deviation (c) and microstructure (d)

the fact that stress relaxation has occurred in the experimental specimens due to microscopic stress peaks. As the phase transformations occur on an atomic level, the residual stresses also arise on a microscopic level. Therefore, if stress peaks form on the microscopic scale, they can influence the equilibrium of the macroscopic stresses and lead to stress relaxation. This effect could be investigated in more detail by using multi-scale simulations.

The experimental results of strategy $2 \mathrm{~A}$ show higher tensile stresses at these positions compared to the simulation. For example, $\sigma_{\mathrm{t}}=222 \mathrm{MPa}$ are measured in average at MP6, in contrast to the calculated stress of $\sigma_{\mathrm{t}}=65 \mathrm{MPa}$. Deviations between the experimental and numerical results of the residual stress values may result from only measuring the residual stresses in the ferritic $\{211\}$ peak in the experiment. Possible influences of the residual stresses in the retained austenite on the macroscopic residual stresses are thus not taken into account in the experimental results in contrast to the simulations. Furthermore, in the simulation model used, only macroscopic effects are considered, which result from an inhomogeneous plastification due to thermal and transformation-induced loads. The influences from microscopic effects like the dislocation density due to austenite transformation, local gradients of yield stress at the phase boundaries or forced dissolution of carbon atoms in the martensitic lattice are only considered in the material characterisation at constant boundary conditions. For example, the ttt diagrams are determined in accordance with the German standard for a microstructure after a ten-minute holding time at austenitising temperature and subsequent direct quenching. The same applies to the determination of the transformation plasticity constants, which are determined by an experimental numerical approach for continuous cooling from the austenitising temperature. This explains a higher deviation between experimental and numerical results, particularly at those locations which have experienced discontinuous cooling.

For the specimens from both strategies, in agreement with the simulations (Figs. 10 and 11) it can be concluded from the hardness values of about $800 \mathrm{HV}$ in the entire cross section of the specimen (Fig. 15b) and the light-microscopic photographs (Fig. 15d) that they are fully hardened martensitic specimens. It is remarkable that the hardness at MP6 is similarly high for both strategies, since in the simulation of strategy $2 \mathrm{~A}$ a lower proportion of martensite is predicted for this location than in strategy $1 \mathrm{~A}$. This indicates a similarly 
high proportion of martensite is formed in reality with both strategies, what is shown slightly differently in the simulation. As shown in Sect. 3.1.1, a pearlitic transformation already takes place in the simulation on the thinwalled side before the martensitic transformation. As a result, the proportion of austenite that can be transformed into martensite is already reduced in the simulation, which leads to a lower fraction of martensitic than can be concluded from the experimental metallographic investigations. Due to the lower martensite transformation, less volume expansion occurs on the thin-walled side. In the experiment, the thermal contraction at MP6 against the resistance of the already cooled adjacent areas is more significant than in the simulation. This results in tensile residual stresses at this location, which are underestimated by the simulation. For better modelling, the pearlite transformation that obviously occurred incorrectly in the simulation would have to be prevented by means of a corrected ttt diagram.

Figure $15 \mathrm{c}$ shows the optically scanned geometry of the specimen from strategy $1 \mathrm{~A}$. The contour plot of the deviation $e$ on this surface indicates the three-dimensional distance in perpendicular direction to the surface of the geometry from strategy $2 \mathrm{~A}$. The deviation of $0 \mathrm{~mm}$ shows a perfect match between the geometry from both strategies. The algebraic sign of the deviation value indicates, if the corresponding area of the geometry from strategy 2A lies outside (positive sign) or inside (negative sign) the workpiece shape from strategy $1 \mathrm{~A}$. The different thermo-mechanical strategies result in local deviations of less than $0.4 \mathrm{~mm}$ maximum.

\subsubsection{Experimentally induced residual stresses in pearlitic components using strategy $1 B$ as well as $2 B$}

The calculated as well as experimentally determined residual stresses on the circumference of the specimens from strategy 1B and 2B are plotted in Fig. 16a. As described in Sect. 3.1.2, the rapid cooling after completed pearlitic transformation leads to a stress gradient with compressive stresses at the surface of the specimen and tensile stresses inside the specimen. In experiments with strategy $2 \mathrm{~B}$, average residual stresses of $\sigma_{\mathrm{t}}=$ $-226 \mathrm{MPa}$ at $\theta=0^{\circ}$ and $\sigma_{\mathrm{t}}=-165 \mathrm{MPa}$ at $\theta=180^{\circ}$ are generated. Compared to the average residual stresses of $\sigma_{\mathrm{t}}=-83 \mathrm{MPa}$ and $\sigma_{\mathrm{t}}=-52 \mathrm{MPa}$ previously generated at these positions by strategy $1 \mathrm{~B}$, the compressive stresses are thus significantly increased. The residual stresses from strategy $2 \mathrm{~B}$ predicted in the simulations, for example $\sigma_{\mathrm{t}}=-297 \mathrm{MPa}$ at $\theta=0$ and $\sigma_{\mathrm{t}}=-130 \mathrm{MPa}$ at $\theta=180^{\circ}$ in average, are close to those determined experimentally.

In the experiments, the residual stresses are generated reproducibly with a maximum standard deviation of $28 \mathrm{MPa}$ in strategy $1 \mathrm{~B}$ and with $38 \mathrm{MPa}$ in strategy $2 \mathrm{~B}$, as shown by the error indicators in Fig. 16.

In the course of the residual stresses from both experiments and simulations, along the angle $\theta$ from $\theta=$ 0 to $\theta=180^{\circ}$, there is a slightly decreasing tendency of the residual stress amounts. This occurs although the entire surface is uniformly exposed to the spray. Higher amounts of stresses occur on the thick-walled side because the strain gradients are more pronounced due to the higher temperature differences between the specimen surface and the specimen core than on the thin-walled side, which cools more quickly in the core.

As the experiments show, slight residual compressive stresses have already resulted for the specimens from strategy $1 \mathrm{~B}$. In the simulations, however, only low stresses in the range of maximum $-11 \mathrm{MPa}$ were found. This indicates that the thermally inhomogeneous contraction between the surface regions and the material core is more pronounced in the experiment than in the simulation. While plastic deformation of the surface area occurs in the experiment, which leads to compressive stresses in the later course of the cooling of the specimen core, mainly elastic effects occur in the simulation, which almost completely balance each to the end of the cooling. It is therefore assumed that the applied flow curves of the supercooled austenite as well as the pearlite from JMatPro are higher than is the case in reality, which inhibits plastification. This problem is obviously more pronounced for smaller thermal strains, such as those occurring during slow cooling in strategy $1 \mathrm{~B}$, than in strategy $2 \mathrm{~B}$, where high thermally induced strain gradients occur. An experimental determination of the phase-specific flow curves is a possibility to improve the accuracy of the modelling. All in all, the results from experiments and simulations for strategy $2 \mathrm{~B}$ are in better agreement than the results for strategy $2 \mathrm{~A}$. This can be explained by the different influencing parameters on the residual stresses that arise in the different strategies. In strategy $2 \mathrm{~A}$, the residual stress state is mainly determined by the transformation-induced strains and the transformation-plastic strains. As already stated, inaccuracies occur as a result of the phase transformation phenomena following the delayed cooling on the thin-walled side, as well as the inaccurate pearlitic phase transformation. In strategy $2 \mathrm{~B}$, hardly any effects due to the phase transformation have an impact. The resulting residual stresses arise as a result of the plastification due to inhomogeneous thermal strains. Deviations may result from the underlying flow behaviour or the thermal strain. This explains why the FE models of the different strategies provide different simulation quality. 

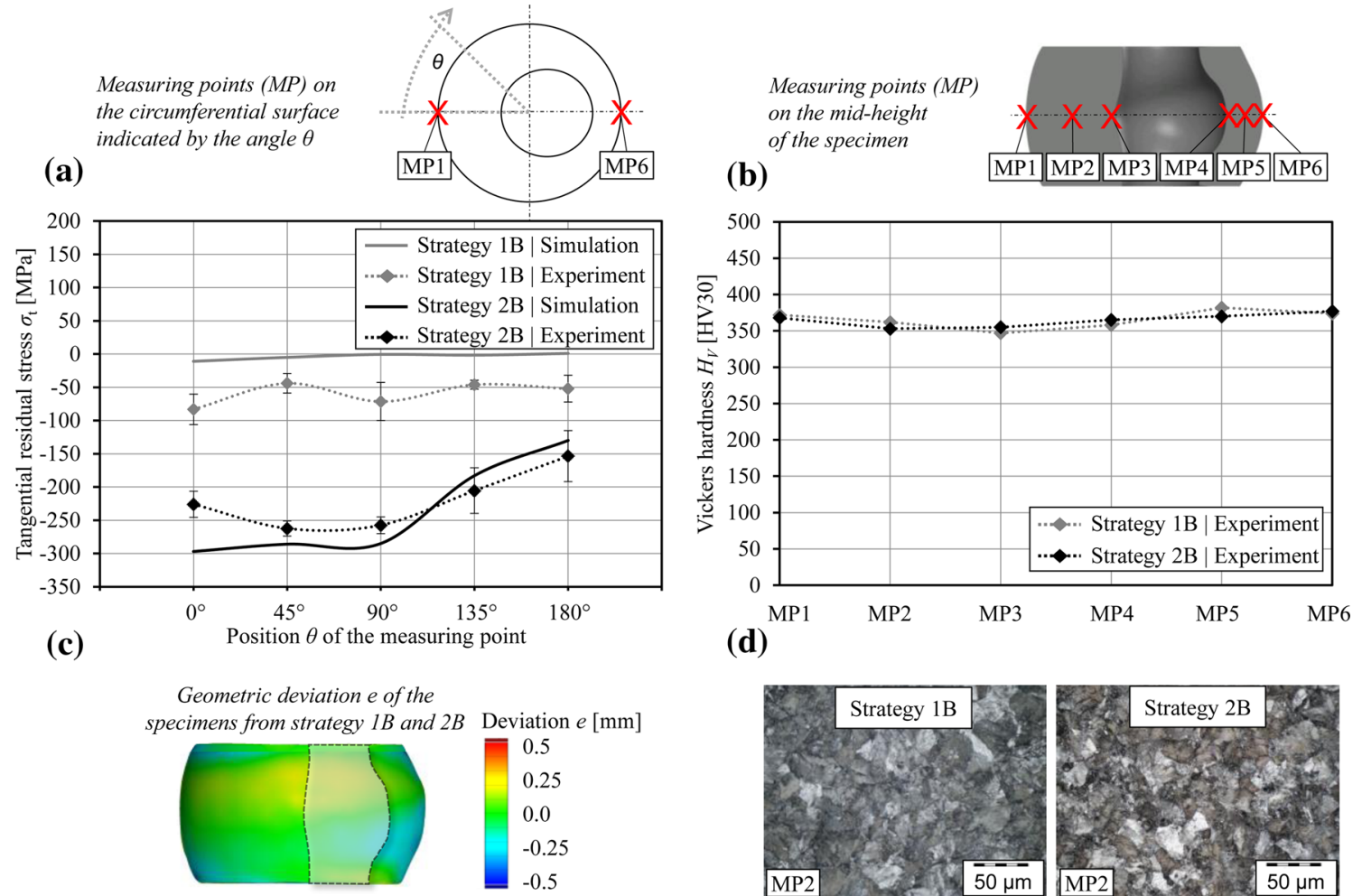

(d)

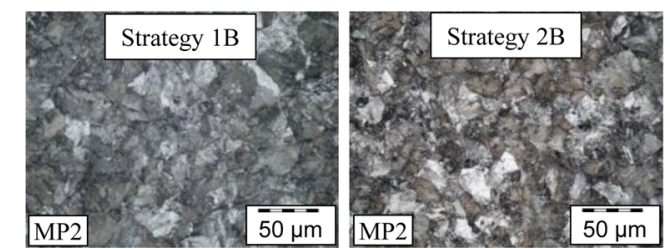

Fig. 16 Comparison of the specimens processed by strategies 1B and 2B with regard to residual stresses from experiments and simulations (a), Vickers hardness (b), geometric deviation (c) and microstructure (d)

For the specimens from both strategies, in agreement with simulations (Fig. 12 and Fig. 13) it can be concluded from the hardness values of about $360 \mathrm{HV}$ in the entire cross section of the specimen (Fig. 16b) and the light-microscopic photographs (Fig. 16d) that a fine-grained pearlitic phase structure also known as troostite is formed. Similar to the martensitic specimens, in the geometric comparison of the specimens from strategy $1 \mathrm{~B}$ and $2 \mathrm{~B}$, local deviations of less than $0.4 \mathrm{~mm}$ maximum are found by optical scanning methods.

Comparing the residual stresses generated on the surfaces of the specimens from strategy $2 \mathrm{~A}$ with those from strategy $2 \mathrm{~B}$, it can be seen that strategy $2 \mathrm{~A}$ is able to generate higher residual stresses on the thickwalled side. However, tensile stresses are present on the thin-walled side. With strategy $2 \mathrm{~B}$, however, residual compressive stresses can be generated over the entire circumference. This is due to the different procedure for the cooling strategies. With strategy $2 \mathrm{~A}$, the specimen is cooled inhomogeneously along the circumference. As a result of the transformation-induced and transformation-plastic effects, stress gradients arise along the circumference of the specimen. In strategy $2 \mathrm{~B}$, the rapid cooling after the completed pearlitic transformation causes a strain gradient between the specimen surface and the specimen core. Thus, residual compressive stresses develop over the entire circumferential surface.

Considering strategies 1A and 1B with simple cooling in water and air, respectively, it is noticeable that in both cases there is no partial cooling of the specimens, but a uniform cooling. As with strategy 2B, temperature gradients develop between the surface and core of the specimen. In strategy $1 \mathrm{~A}$, the martensitic volume expansion in the core of the specimen at the end of cooling leads to tensile stresses on the entire surface of the specimen. In strategy 1B, in contrast, the thermal contraction in the core of the specimen at the end of cooling causes slight residual compressive stresses against the resistance of the already cooled surface areas.

\section{Conclusion and outlook}

This work aims at the generation of an advantageous surface-near compressive residual stress distribution in hot-formed components by intelligent process control with tailored cooling. Using a spray cooling system a reference part of a bulk metal forming process is exposed to an adapted cooling process. Adapted cooling is 
achieved by partial or temporal instationary exposure of the specimens to water-air spray. Thus, macroscopic effects such as local plastification due to inhomogeneous strains as a result of thermal- and transformationinduced loads can be controlled in order to finally customise the residual stress distribution. Applications for hot-formed components often require special microstructural properties, which guarantee a certain hardness or ductility. For this reason, the scientific challenge of this work is to generate different residual stress distributions at the surface of components with the same microstructural properties by means of a process chain of hot forming.

For this purpose a hot-forming processes with four different cooling strategies are investigated using numerical simulations and experimental tests. Strategies 1A and 1B involve simple cooling of the specimens from the forming heat in water and atmospheric air. These strategies result in martensitic components with tensile residual stresses or pearlitic specimens with low compressive residual stresses. Strategies 2A and 2B are developed by numerical studies and involve tailored cooling by spray. Tensile residual stresses between 138 and $216 \mathrm{MPa}$ in average are measured at the surface of the specimens from strategy 1A. After process optimisation, average residual compressive stresses of $-407 \mathrm{MPa}$ are measured on the specimens from strategy 2A with adapted cooling at MP1. However, tensile residual stresses of $222 \mathrm{MPa}$ in average also occur at MP6 in this strategy. Average residual compressive stresses between $-52 \mathrm{MPa}$ and $-83 \mathrm{MPa}$ are measured on the surface of the specimens from strategy $1 \mathrm{~B}$. After process optimisation, average residual compressive stresses of $-153 \mathrm{MPa}$ up to $-262 \mathrm{MPa}$ are measured over the entire circumference of the specimen from strategy $2 \mathrm{~B}$ with tailored cooling.

Based on the numerical and experimental analyses, this work demonstrates that it is possible to influence and even invert the sign of the residual stresses of a component by controlling the macroscopic effects mentioned above. This considerable change in residual stresses is achieved only by tailored cooling. The numerically designed strategies proved capable of generating advantageous stress distributions at the surfaces while maintaining the geometry and microstructural properties of the components.

Based on the numerical analyses in Sect. 3.1, different influencing factors are identified in strategies 2A and $2 \mathrm{~B}$, which affect the residual stress state. For example, in the manufacturing of martensitic specimens in strategy $2 \mathrm{~A}$, strains due to transformation-induced and transformation plastic effects are responsible for the development of the residual stress state. In the manufacturing of the pearlitic specimens in strategy $2 \mathrm{~B}$, on the other hand, the plastic strains that arise as a result of the inhomogeneous cooling between the surface and core of the specimens are mainly responsible for the resulting residual stresses.

The residual stresses are predicted with good accuracy by the FE simulations in the course of the process design. The temperature boundary conditions in the different strategies can be simulated well with the determined HTC values, as the comparison with experimental results shows. However, some aspects are identified which can contribute to the improvement of the simulation quality.

To improve the simulation of the development of residual stresses in strategy $2 \mathrm{~A}$, for example, an application-oriented material characterisation with regard to transformation-induced and transformationplastic effects after delayed cooling is recommended. In addition, the calculation accuracy of the phase fractions can be enhanced by adapting the ttt diagram used. A further increase in the simulation quality for the case of strategy $2 \mathrm{~B}$ could be achieved by experimentally determining the pearlitic flow curves. This makes it possible to better model the plastic deformation as a result of inhomogeneous thermal strains between the surface and core of the specimen and to better calculate the residual stresses.

Furthermore, when calculating residual stresses in hot forming, it is also important to take microscopic influences into account. In this context, the phase transformations during cooling play an important role. These phase transformations occur at the atomic level. Therefore, if stress peaks form on the microscopic scale, they can influence the equilibrium of the macroscopic stresses and lead to stress relaxation. Since these effects cannot be captured with a purely macroscopic model, another working group is already investigating the microscopic influences on the residual stresses in the analyses by means of multi-scale simulations within the scope of the project [50]. The aim is to gain a better understanding of the development of residual stresses and to contribute in improving the macroscopic FE models as efficient virtual tools for process analysis.

Another topic for future work is the consideration of residual stress distributions within the specimens. Up to now, only the residual stresses from X-ray analyses on the surfaces of the specimens have been investigated, as these are primarily considered to be advantageous for the fatigue strength and wear resistance of the component. However, it is also important to include the residual stresses inside a component in the investigations.

On the one hand, fatigue cracks were found in some investigations not only on the surface but also underneath the surface, for example, in roller bearing rings [51]. It is therefore necessary to investigate which distribution of compressive residual stresses in the depth profile provides the most effective increase in fatigue 
strength. On the other hand, the evaluation of the FE models on the basis of the residual stress distributions in the volume of the specimens is very important, since the comparison with experimental results from X-ray analyses only provides a validation for surface-near points. For example, the contour method can be used to investigate the residual stresses in the volume of the specimens [52].

In future research work it is planned to transfer the knowledge gained to other materials as well as to complex and industrially relevant components. Here, components such as bearing rings, gear wheels or shafts may be considered for optimising the residual stresses aiming at improved properties. Overall, the focus is on improving component performance in operation while at the same time upgrading manufacturing regarding cost efficiency and productivity using integrated tailored cooling.

Acknowledgement The authors are very grateful to Dipl.-Ing. J. Diefenbach for his kind support regarding experimental applications of the spray cooling system.

Funding Open Access funding enabled and organized by Projekt DEAL.. This study was funded by the German Research Foundation (DFG, Deutsche Forschungsgemeinschaft)-374871564 (BE 1691/223-2) within the priority program SPP 2013.

\section{Declarations}

Conflicts of interest The authors declare no conflict of interest.

Open Access This article is licensed under a Creative Commons Attribution 4.0 International License, which permits use, sharing, adaptation, distribution and reproduction in any medium or format, as long as you give appropriate credit to the original author(s) and the source, provide a link to the Creative Commons licence, and indicate if changes were made. The images or other third party material in this article are included in the article's Creative Commons licence, unless indicated otherwise in a credit line to the material. If material is not included in the article's Creative Commons licence and your intended use is not permitted by statutory regulation or exceeds the permitted use, you will need to obtain permission directly from the copyright holder. To view a copy of this licence, visit http://creativecommons.org/licenses/by/4.0/.

\section{References}

1. Semiatin, S. L.: "Introduction to Forming and Forging Processes," In: Totten, G., Howes, M., Inoue, T. (eds.) ASM Metals Handbook Volume 14 - Forming and Forging, Novelty, Ohio, USA, ASM International (1998).

2. Gegel, H. L. Malas, J. C. : "Computer-Aided Process Design for Bulk Forming," In: Semiatin, S. L. (ed.) Handbook of Forming and Forging Volume 14, Novelty, Ohio, USA, ASM International (1993).

3. Behrens, B.-A., Olle, P.: "Consideration of phase transformations in numerical simulation of press hardening," Steel Research International, pp. 784-790 (2007).

4. Behrens, B.-A., Olle, P., Schäffner, C.: "Process Simulation of Hot Stamping in Consideration of Transformation-Induced Stresses," Numisheet, pp. 557-562 (2008).

5. Denis, S., Gautier, E., Simon, A., Beck, G.: "Stress-phase-transformation interactions - basic principles, modelling and calculation of internal stresses," Materials Science and Technology, pp. 805-814 (1985).

6. Behrens, B., Schrödter, J.: "Numerical Simulation of Phase Transformation during the Hot Stamping Process,” In: Proceedings of the 5th International Conference on Thermal Process Modeling and Computer Simulation, no. 17-18, pp. 179-190 (2014).

7. Simsir, C.: 3D Finite Element Simulation of Steel Quenching in Order to Determine the Microstructure And Residual Stresses, Middle East Technical University (2008).

8. Behrens, B.-A., Bouguecha, A., Bonk, C., Chugreev, A.: Numerical and experimental investigations of the anisotropic transformation strains during martensitic transformation in a low alloy Cr-Mo steel 42CrMo4. Procedia Eng. 2017(207), 1815-1820 (2017)

9. Löhe, D., Lang, K.-H., Vöhringer, O.: "Residual Stresses and Fatigue Behavior,” In: Totten, G., Howes, M., Inoue, T. (eds.) Handbook of residual stresses and deformation, Novelty, Ohio, USA, ASM International (2002).

10. Withers, P.J.: Residual stress and its role in failure. Rep. Prog. Phys. 70, 2211-2264 (2007)

11. Kritzler, J., Wübbenhorst, W.: "Inducing Compressive Stresses through Controlled Shot Peening," In: Totten, G., Howes, M., Inoue, T. (eds.) Handbook of Residual Stress and Deformation, Novelty, Ohio, USA, ASM International (2002).

12. McClung, R.C.: A literature survey on the stability and significance of residual stresses during fatigue. Fatigue Fract. Eng. Mater. Struct. 30, 173-205 (2007)

13. Mattson, R. L.: "Fatigue, Residual Stresses and Surface Cold Working," In: Proceedings of International Conference Fatigue of Metals, American Society of Mechanical Engineers, pp. 593-603 (1956).

14. Funatani, K., Parkerizing, N.: "Residual Stresses during Gear Manufacture," Handbook of Residual Stress and Deformation of Steel (2002).

15. Löhe, D., Hoffmann, J.E.: Influence of Macro Residual Stresses on the Fatigue Behavior Smooth and Notched Specimens Made from a High Strength Steel. J. Mater. Manufact. 111, 704-710 (2002) 
16. Kobasko, N. I., Morganyuk, V. S., Dobrivecher, V. V.: "Control of Residual Stress Formation and Steel Deformation during Rapid Heating and Cooling," In: Totten, G., Howes, M., Inoue, T. (eds.) Handbook of Residual Stress and Deformation, Novelty, Ohio, USA, ASM International (2002).

17. Easton, D., Rahimi, S., Aylott, C., Shaw, B.: "Gears machined from forged billet and as-received bar develop tensile residual stress in the core of the gear following full heat treatment," Gear Solutions, pp. 29-36 (2019).

18. Reti, T.: Residual Stresses in Carburised, Carbonitrided and Case-hardened Components. Heat Treat. Met. 30, 83-96 (2003)

19. Morganyuk, V.S., Kobasko, N.I., Kulakov, A.N.: Predicting the deformation of bearing races during hardening. Heat Treat. Technol. 24, 620-623 (1982)

20. Grum, J.: "Induction Hardening," In: Totten, G., Howes, M., Inoue, T. (eds.) Handbook of Residual Stress and Deformation, Novelty, Ohio, USA, ASM International.

21. Rodman, D.: Induction hardening of spur gearwheels made from $42 \mathrm{CrMo} 4$ hardening and tempering steel by employing spray cooling., vol. 82, Steel Research International, pp. 329-336 (2011).

22. Grum, J.: How to Select Induction Surface Hardening and Finished Grinding Conditions in Order to Ensure High Compressive Residual Stresses on Machine Parts Surface. Mater. Sci. Forum 404-407, 2599-2604 (2003)

23. Mittemeijer, E.J.: The Influence of Tempering and Surface Conditions on the Fatigue Behaviour of Surface Induction Hardened Parts. Mater. Sci. Forum 102-104, 319-334 (1992)

24. Behrens, B.-A., Bleck, W., Bach, F.-W., Brinksmeier, E., Fritsching, U., Liewald, M., Zoch, H.-W.: Resource-Efficient Process Chains for High Performance Parts. Key Eng. Mater. 504-506, 151-156 (2012)

25. Hougardy, H.P.: Umwandlung und Gefüge unlegierter Stähle, vol, 2nd edn. Stahleisen GmbH, Düsseldorf (1990)

26. Bobbert, D.: Untersuchungen über das Vergüten aus der Schmiedewärme. Universität Hannover, Hannover (1968)

27. Wegner, K.-W.: Werkstoffentwicklung für Schmiedeteile im Automobilbau. Automob. Z. 100(12), 918-927 (1998)

28. Weißbach, W.: Werkstoffkunde - Strukturen, Eigenschaften, Prüfung. Vieweg Verlag, Wiesbaden (2007)

29. Haimbaugh, R.E.: Practical Induction Heat Treating, pp. 123-130. ASM International, Novelty, Ohio, USA (2001)

30. Beitz, H., Beitz, T.: Quenchants for induction hardening - Applications and care. BHM Berg- Huettenmaenn. Monatsh. 150, 96-100 (2005)

31. Kaymak, Y.: Simulation of Metal Quenching Processes for the Minimization of Distortion and Stresses. Otto-von-GuerickeUniversität Magdeburg, Magdeburg (2007)

32. Nürnberger, F., Diekamp, M., Moritz, J., Wolf, L., Hübner, S., Behrens, B.-A.: "Spray Cooling of Early Extracted Hot Stamped Parts," In: TMS 2014: 143rd Annual Meeting \& Exhibition, pp. 983-990 (2014).

33. Behrens, B.-A., Maier, H., Neumann, A., Moritz, J., Hübner, S., Gretzki, T., Nürnberger, F., Spiekermeier, A.: Press Hardening of Tubes with Additional Interior Spray Cooling. Int. J. Mech. Mechatron. Eng. 9, 957-963 (2015)

34. Breuer, M.: Verknüpfung von Wärmebehandlung und Formgebung beim Präzisionsschmieden von Verzahnungen. VDIVerlag GmbH, Düsseldorf (2000)

35. Krause, C., Hassel, T., Frovol, I., Gretzki, T., Kästner, M., Seewig, J., Bormann, D., Bach, F.-W.: Randschichtvergüten von Ritzelwellen mittels Wasser-Luft-Sprühkühlung. HTM - Haerterei-Technische Mitteilungen 63, 22-26 (2008)

36. Brzoza, M.: Reduzierung von Eigenspannungen und Verzug durch örtliche Beeinflussung der Abkühlung. Otto-von-GuerickeUniversität Magdeburg, Magdeburg (2006)

37. Günter, S., Stöferle, T.: Handbuch der Fertigungstechnik, Band 4/2 Wärmebehandlung. Carl Hanser Verlag, München (1987).

38. Schröder, R., Scholtes, B., Macherauch, E.: Rechnerische und röntgenographische Analyse der Eigenspannungsausbildung in abgeschreckten Stahlzylindern. HTM - Haerterei-Technische Mitteilungen 39, 280-267 (1984)

39. Behrens, B.-A., Schröder, J., Brands, D., Scheunemann, L., Niekamp, R., Chugreev, A., Sarhil, M., Uebing, S., Kock, C.: "Experimental and numerical investigations on the development of residual stresses in thermo-mechanically processed Cr-alloyed steel 1.3505," Metals, no. 9(4) (2019).

40. Behrens, B.-A., Chugreev, A., Kock, C.: "Macroscopic FE-simulation of residual stresses in thermo-mechanically processed steels considering phase transformation effects," In: XIV International Conference on Computational Plasticity. Fundamentals and Applications, pp. 211-222 (2019).

41. Simsir, C., Hakan Gür, C.: "3D FEM simulation of steel quenching and investigation of the effect of asymmetric geometry on residual stress distribution," J. Mater. Process. Technol. 207(1-3), 211-221 (2008)

42. DIN EN 15305:2009-1, Non-destructive testing - Test method for residual stress analysis by X-ray diffraction, Beuth Verlag, Berlin (2008).

43. Eigenmann, B., Macherauch, E.: Röntgenographische Untersuchung von Spannungszuständen in Werkstoffen-Teil 3. Materialwissenschaften Und Werkstofftechnik 27, 426-437 (1996)

44. DIN EN ISO 6507-1, Metallic Materials - Vickers Hardness Test - Part 1: Test Method; Technical Report, Beuth-Verlag, Berlin, Germany (2018).

45. Behrens, B.-A., Chugreev, A., Kock, C. : "Experimental-numerical approach to efficient TTT-generation for simulation of phase transformations in thermomechanical forming processes," In: IOP Conference Series, Materials Science and Engineering, no. 461 (2018).

46. Acht, C., Dalgic, M., Frerichs, F., Hunkel, H., Irretier, A., Lübben, T., Surm, H.: Ermittlung der Materialdaten zur Simulation des Durchhärtens von Komponenten aus 100Cr6. J. Heat Treatment Mater. 63, 234-244 (2008)

47. "JMatPro. Practical software for materials propertie," Sente Software Ldt., [Online]. Available: https://www.sentesoftware. co.uk/jmatpro. [Accessed 0801 2020].

48. Special Metals Co, New Hartford, New York, USA, [Online]. Available: http://www.specialmetals.com/assets/smc/540 documents/pcc-8064-sm-alloy-handbook-v04.pdf. [Accessed 0801 2020].

49. Behrens, B.-A., Bouguecha, A., Vucetic, M., Chugreev, A.: "Advanced Wear Simulation for Bulk Metal Forming Processes," In: MATEC Web of Conferences (2016).

50. Uebing, S., Brands, D., Scheunemann, L., Schröder, J.: Residual stresses in hot bulk formed parts: two-scale approach for austenite-to-martensite phase transformation. Arch. Appl. Mech. 91, 1-18 (2021)

51. Pape, F., Coors, T., Poll, G.: "Studies on the Influence of Residual Stresses on the Fatigue Life of Rolling Bearings in Dependence on the Production Processes," Frontiers in Mechanical Engineering, 6(56) (2020). 
52. Prime, M., Gonzales, A.: “The Contour Method: Simple 2-D Mapping of Residual Stresses," Oxford, UK (2000).

Publisher's Note Springer Nature remains neutral with regard to jurisdictional claims in published maps and institutional affiliations. 